https://doi.org/10.11646/zootaxa.4524.5.1

http://zoobank.org/urn:Isid:zoobank.org:pub:B8D8C69B-D05A-4C0F-96D0-46325EC93543

\title{
Six new Cyrtodactylus (Squamata: Gekkonidae) from northeast India
}

\author{
ISHAN AGARWAL ${ }^{1,2,3,8}$, STEPHEN MAHONY ${ }^{4,5}$, VARAD B. GIRI ${ }^{3,6}$, \\ R. CHAITANYA ${ }^{7}$ \& AARON M. BAUER ${ }^{1}$ \\ ${ }^{1}$ Department of Biology, Villanova University, 800 Lancaster Avenue, Villanova, Pennsylvania 19085, USA \\ ${ }^{2}$ Centre for Ecological Sciences, Indian Institute of Science, Bangalore 560012, India \\ ${ }^{3}$ National Centre for Biological Sciences, Tata Institute of Fundamental Research, Bangalore 560065, India \\ ${ }^{4}$ School of Biology and Environmental Science, University College Dublin, Belfield, Dublin 4, Ireland \\ ${ }^{5}$ Department of Life Sciences, The Natural History Museum, London SW7 5BD, UK \\ ${ }^{6}$ NIDUS, 1903, Shubh Kalyan, Nanded, Pune, 411041, India \\ ${ }^{7} 508,8$ B Cross, Asha Township, Doddagubbi village, Bangalore, 560077, India \\ ${ }^{8}$ Corresponding author. E-mail: ishan.agarwal@gmail.com
}

\begin{abstract}
We use mitochondrial sequence data to identify divergent lineages within the gekkonid genus Cyrtodactylus in northeast India and use morphological data to describe six new species from within the Indo-Burma clade of Cyrtodactylus. The new species share an irregular colour pattern but differ from described species from the region in morphology and mitochondrial sequence data ( $>11 \%$ uncorrected pairwise sequence divergence). Three new species are from along the Brahmaputra River and three are from mountains south of the Brahmaputra, including the largest Cyrtodactylus from India and the fifth gecko to be described from a major Indian city, Guwahati.
\end{abstract}

Key words: Cyrtodactylus khasiensis, endemic species, morphology, Myanmar, ND2, taxonomy

\section{Introduction}

Among the most spectacular landscapes on Earth, the Himalayas were formed by the collision of the northward drifting Indian Plate and Eurasia, which began 50 million years ago (Ali \& Aitchinson 2008; Bouilhol et al. 2013). The Himalayan region includes the tallest mountains in the world and is a topographically and climatically heterogeneous landscape, overlapping with the Himalaya Hotspot and part of the Indo-Burma Hotspot (Mittermeier et al. 2004). Indicative of how little is known of the biodiversity of the region, several morphologically distinct vertebrates have been described in the last two decades from the Himalayas and IndoBurma (Slowinski \& Wüster 2000; Bauer 2002, 2003; Sinha et al. 2005; Athreya 2006; Mahony 2009 a; Das et al. 2010; Sondhi and Ohler 2011; Kamei et al. 2013; Datta-Roy et al. 2013; Mahony et al. 2013; Grismer et al. 2018 a,b,c; Agarwal et al. 2018a, b; Britz et al. 2018).

The most diverse reptile genus in the circum-Himalayan region is Cyrtodactylus Gray, with 50 species distributed across Bangladesh, southern China (Tibet), Myanmar, Nepal, Pakistan and the western Himalayas and northeast of India (Schleich \& Kästle 2002; Li 2007; Mahony et al. 2009; Shi \& Zhao 2010; Bauer et al. 2013; Agarwal et al. 2018a, b; Grismer et al. 2018a, c; Uetz et al. 2018). Over two-thirds of these species have been described since 2000 - and Myanmar is notable for the dramatic increase in Cyrtodactylus species diversity. Just six species were known in 2001, before the description of nine species in 2002-2003 (Bauer 2002, 2003) and 18 species from 2009-2018 (Mahony 2009b; Connette et al. 2017; Grismer et al. 2018, 2018b) - for a total of 33 currently recognized species in mainland Myanmar (Mahony 2009b; Grismer et al. 2018a, b). The increase in species diversity has largely been driven by surveys by the California Academy of Sciences and La Sierra University, USA. Myanmar is also the only region in which the Indo-Burma and Southeast Asian clades co-occur (Grismer et al. 2018a, c). 
West of Myanmar are northeast India and Bangladesh, where the Himalaya and Indo-Burma Biodiversity Hotspots abut. In sharp contrast to Myanmar, only five species of Cyrtodactylus are currently recognized from northeast India and Bangladesh, all from within the Indo-Burma clade (Agarwal et al. 2018a, b). Genetic data from across the region, on the other hand, have revealed several undescribed lineages (Agarwal et al. 2014; Agarwal et al. 2018a, b), with the historical lumping of many lineages with superficially similar colour patterns from across the region into the catchall species Cyrtodactylus khasiensis (Jerdon) (e.g. Smith 1935; Pawar and Birand 2001; Das et al. 2007; Agarwal et al. 2010; Purkayastha et al. 2011), obfuscating the true range of morphological variation within $C$. khasiensis. The recent descriptions of two new Cyrtodactylus species from northeast India, the circumscription of described species to specific ranges of characters and distributional data, and a backbone phylogeny (Wood et al. 2012; Agarwal et al. 2014), allows the formal description of unnamed populations. In this paper, we use morphological data to describe six genetically divergent lineages of Cyrtodactylus as new species, from within the mountain and lowland clades in northeast India as identified by Agarwal et al. (2014).

\section{Material and methods}

Molecular data. Our alignment included the ND2 gene (1038 nucleotides) for members of the mountain and lowland clades (or clades M, N; Agarwal et al. 2014) from within the Indo-Burma clade of Cyrtodactylus, which include the six new species. The most closely related species outside this group, Cyrtodactylus "sp. CHNG" (Agarwal et al. 2014), from eastern Arunachal Pradesh was used as the outgroup (Table 1). Uncorrected \% pairwise sequence divergence ( $p$-distance) between members of clades $\mathrm{M}$ and $\mathrm{N}$ was calculated in MEGA 5.2.2 (Tamura et al. 2011). As our dataset had just a single individual per population, we did not conduct species delimitation analyses and used the 8\% uncorrected $p$-distance cutoff for ND2 that Agarwal et al. (2014) applied to identify putative new species. A maximum-likelihood phylogeny was constructed with codon partitioned ND2 data and the GTR + G model of sequence evolution using the raxmlGUI 1.3 (Silvestro and Michalak 2012) that implements RAxML HPC 7.4.2 (Stamatakis 2006), with 10 independent ML runs and support assessed with 1000 rapid bootstraps.

Morphology. We examined specimens using a stereo microscope and took measurements and scale counts on the right side of the body where possible (Appendix 1 has a list of material examined). We recorded the following measurements to the nearest $0.1 \mathrm{~mm}$ with calipers (as defined by Bauer 2003): BW, body width; CL, crus length; EE, orbit to ear distance; EL, ear length; FL, forearm length; HH, head height; HL, head length; HW, head width; IN, internarial distance; IO, interorbital distance; NE, nostril to eye distance; ED, eye diameter; SE, snout to eye distance; SVL, snout to vent length; TL, tail length; TRL, trunk length; TW, tail width; and (maximum) width of postmentals. We also counted the number of longitudinal rows of tubercles around the body at mid-body (dorsal tubercle rows, DTR), ventral scale rows (MVSR; counted at midbody, between ventrolateral folds or when fold was absent, as demarcated by lowest row of tubercles/ transition of granular juxtaposed dorsal scales to ventral subimbricate scales), paravertebral tubercles (PVT, from posterior edge of forelimb insertion to anterior edge of hindlimb insertion), and noted the presence or absence of a ventrolateral fold. Digits are numbered from inner (I) to outer (V); SL and IL counted from the labial in contact with the rostral and mental scale on each side, respectively, to the angle of the jaw; numbers in parentheses following SL indicate count at mid-orbit. We counted precloacal pores (PcP, pores only in preclocacal series), precloacofemoral pores (PcFP, when a continuous or near continuous series extends onto femurs) and femoral pores on each thigh (FP, separated from PcP by at least three poreless scales). Transversely expanded subdigital lamellae were counted in a basal series (from the base of the digit to and including the large scale at inflection) and a distal series (from the large scale at inflection and up to but not including the claw sheath). Smaller scales at the base of the digit and near the inflection were excluded from these counts. Colour descriptions were made from digital photographs of specimens in life or based on preserved material if life fphotographs were unavailable.

Comparisons were made with material in the collections of the Bombay Natural History Society, Mumbai, India (BNHS); California Academy of Sciences, San Francisco, USA (CAS); Centre for Ecological Sciences, Bangalore, India (CES); Natural History Museum, London, UK (NHMUK; formerly British Museum of Natural History, BMNH); and Zoological Survey of India, Kolkata, India (ZSI). We used published measurements and characters for a few species that we could not examine (Darevsky et al. 1997; Li 2007). We limit comparisons to 
congeners that are geographically proximate (distributed in northeast India, eastern Nepal and Myanmar, west of the Salween River), including those that are demonstrated to be phylogenetically closely related members of the clades to which the new species belong (Figs. $1 \& 2$ ).

\section{Results}

We recovered the same topology as Agarwal et al. 2014, with moderate support for the south of Brahmaputra clade (Fig. 2). A basal split within the south of Brahmaputra clade separates a mountain (clade M in Agarwal et al. 2014) and lowland clade (clade $\mathrm{N}$ ), which contain a total of seven, unnamed divergent lineages. The lowland clade includes taxa from lowlands south of the Brahmaputra-the species C. ayeyarwadyensis Bauer, C. khasiensis, and C. tripuraensis Agarwal, Mahony, Giri, Chaitanya and Bauer; and the new species C. guwahatiensis sp. nov., $C$. kazirangaensis sp. nov., and $C$. septentrionalis sp. nov. The mountain clade has three species from Myanmar, $C$. brevidactylus Bauer, C. chrysopylos Bauer, and $C$. gansi Bauer; and the new species $C$. jaintiaensis sp. nov., $C$. montanus sp. nov., $C$. nagalandensis sp. nov. and the unnamed $C$. sp. Mizoram from mountains in northeast India. ND2 $p$-distance results are provided in Table 2 and are discussed below in comparisons sections. We describe six of these genetically divergent lineages from across the lowland and mountain clades as new species below.

\section{Taxonomy}

\section{Cyrtodactylus guwahatiensis sp. nov.}

Figs. 3-5.

Holotype. Adult male (BNHS 2146, field number CES09/1127), collected from Hengrabari Road, Guwahati City, Kamrup Metropolitan district, Assam state, India $\left(26.16193^{\circ} \mathrm{N}, 91.78298^{\circ} \mathrm{E}\right.$, elevation $<100 \mathrm{~m}$ asl.) by Ishan Agarwal, 11 June 2009.

Diagnosis. Cyrtodactylus guwahatiensis sp. nov. can be distinguished from all congeners by: its moderate body size (SVL up to at least $67.8 \mathrm{~mm}$ ); 10 supralabials; nine infralabials; 23 or 24 longitudinal rows of bluntly conical, feebly keeled dorsal tubercles; tubercles extending till third segment of tail; 35 paravertebral tubercles; $\sim 34$ ventral scales between ventrolateral folds; no precloacal groove; 26 precloacofemoral pores in a discontinuous series interspersed by 11 unpored scales; a row of enlarged scales above and below precloacal pore-bearing scales, slightly larger than pore-bearing scales; 16 total subdigital lamellae beneath toe IV of pes; subcaudal scalation of original tail without enlarged plates; dorsal pattern of 8-10 transverse rows of two or three pale buff blotches outlined by thick dark reticulations. Tail with alternating dark and lighter bands.

Etymology. The specific epithet is a toponym for the type locality of the species, Guwahati, the largest city in Assam and northeast India.

Description of holotype. Holotype in generally good preservation condition except folds on abdomen, head bent towards right, tail tip removed as tissue voucher, constriction just anterior to hind limb insertion due to overzealous tag tying. Adult male, SVL $67.8 \mathrm{~mm}$. Head long (HL/SVL 0.26; HW/HL 0.67), dorsoventrally depressed (HD/HW 0.58), distinct from neck; loreal region somewhat inflated, interorbital area flat, canthus rostralis not prominent; snout short (SE/HL 0.43), twice as long as orbit diameter (ED/SE 0.51); scales on forehead, canthus rostralis and snout homogeneous, those on forehead smaller, roughly hexagonal, juxtaposed, weakly pointed; scales on interorbital and occipital region heterogeneous, granular, intermixed with larger, rounded, conical tubercles which are two to three times larger than adjacent granules, enlarged tubercles sparse on interorbital region and dense on occiput, single row of enlarged pointed tubercles on the eyelids, one or two scale rows from supraciliaries on each side. Eye small (ED/HL 0.22); pupil vertical with crenulated margins; supraciliaries small, mucronate, decreasing in size towards posterior and anterior end of orbit, largest about onethird the way from anterior edge of orbit; ear opening oval, obliquely oriented; eye to ear distance approximately half eye diameter (ED/SE 0.51). Rostral wider $(2.7 \mathrm{~mm})$ than deep $(1.7 \mathrm{~mm})$, partially divided dorsally by weakly developed rostral groove; single much enlarged supranasal on either side, separated by single small internasal, approximately same size as enlarged scales on snout; rostral in contact with supralabials I, nostrils, supranasals and 
an internasal; nostrils semicircular, laterally oriented, posterior half covered by nasal pad, each in broad contact with rostral and surrounded by supranasal, supralabial I, and 3-4 postnasals; three or four rows of scales separate orbit from supralabials; mental wider $(2.3 \mathrm{~mm})$ than long $(2.0 \mathrm{~mm})$, triangular, two well-developed postmentals on either side, inner pair in broad contact $(1.2 \mathrm{~mm})$ behind mental, twice the size $(2.1 \mathrm{~mm})$ of and separating outer pair $(1.0 \mathrm{~mm})$; inner postmentals bordered by mental, infralabial I, outer postmental and eight gular scales; outer postmental bordered by inner postmental, infralabials I and II, and five gular scales of dissimilar sizes on either side; eight supralabials to midorbital position and 10 supralabials to angle of jaw on each side, bordered by a row of large, flat, keeled, elongate scales; nine infralabials on each side, infralabials II to VI bordered by one or two rows of enlarged scales, increasing in size anteriorly.

Body slender, short (TRL/SVL 0.47) with ventrolateral folds; dorsal scales heterogeneous, mostly rounded granules, intermixed with irregularly arranged, enlarged tubercles, bluntly conical and keeled throughout, becoming more conical and slightly smaller towards flanks, ventrolateral folds with single row of scattered enlarged, smooth tubercles; tubercles extend from occipital region posteriorly onto tail base; tubercles on nape smaller than those of dorsum; enlarged tubercles on tail flat, weakly pointed and feebly keeled; 23 or 24 dorsal tubercles across mid-dorsum; 35 paravertebral tubercles; ventral scales much larger than dorsals, smooth, cycloid, imbricate to subimbricate; slightly smaller in size under thighs, two rows of enlarged scales between precloacal pores and vent; $\sim 34$ ventral scales between ventrolateral tubercle rows; gular region with small granular scales throughout except a few anterior scales bordering the postmentals that are larger, juxtaposed. Eleven distinct porebearing precloacal scales in a continuous series, separated on each side by one unpored scale from a discontinuous series of smaller pore-bearing femoral scales; six femoral pores on the right and nine on the left with five and four unpored scales in each series, respectively; no precloacal groove; hemipenal bulge distinct.

Fore and hind limbs slender, short (FL/SVL 0.14, CL/SVL 0.16); digits short, strongly inflected at each joint, all bearing robust recurved claws; five subdigital lamellae in basal series and nine in distal series with two nonlamellar granules at inflection (digit IV, right manus); seven basal and nine distal lamellae with three non-lamellar granules at inflection (digit IV, right pes), inter-digital webbing absent on manus, rudimentary between toes I to IV; relative length of digits: I $<$ II $<$ V $<$ III $<$ IV (right manus) and I $<$ II $<$ III $<$ V $<$ IV (right pes); scales on palms and soles smooth, flat, subimbricate; scales on fore limbs heterogeneous, composed of flat, weakly pointed, feebly keeled, subimbricate scales on upper arms, those on forearms heterogeneous, granular close to elbows with slightly enlarged tubercles, becoming flat, smooth and subimbricate anteriorly, ventral portion covered with small granular scales; scales on hind limbs heterogeneous, dorsal part of thighs and shanks with larger, conical granular scales, intermixed with scattered, enlarged, conical, feebly keeled tubercles; anterior portion of thighs and ventral aspect of hind limbs with much enlarged, smooth, imbricate scales.

Tail original, incomplete, rounded, slender, tapering; divided into indistinct caudal segments; two to three rows of enlarged, flat, weakly pointed, smooth, tubercles positioned transversely on first three segments of tail, remaining dorsal caudal scales smooth, rounded, subimbricate, similar in size dorsally but becoming larger on lateral aspect; subcaudal scales larger, smooth, imbricate and heterogeneous in size, no enlarged plates. Three enlarged, smooth, conical post cloacal spurs on each side of tail base.

Colouration in life (Fig. 3) Dorsal ground colour of body, limbs and tail dark-brown, head brown; top of head with indistinct light yellow blotches forming larger indistinct paired markings on occiput; labials lighter than dorsum of head; two light yellow narrow postorbital streaks not extending as far as ear opening; neck with pair of light tan spots, 8-10 transverse rows of two or three indistinct pale buff coloured blotches outlined by thick dark reticulations extending from above fore limb insertions to tail base, mid-dorsal line confluent with central light spots; limbs with indistinct crossbars and a few lighter blotches; eight dark and seven light caudal bands, dark bands approximately twice as wide as light bands; iris grey-silver with dark reticulations, pupil bordered by brown.

Colouration in preservative (Figs. 4 \& 5). Dorsal ground colour of body, limbs and tail light-brown, head brown; top of head with indistinct light blotches forming larger indistinct paired markings on occiput; labials similar in shade to dorsum of head; two light narrow postorbital streaks not extending as far as ear opening; neck with pair of light tan spots, 8-10 transverse rows of two or three indistinct pale buff coloured blotches outlined by thick dark reticulations extending from above fore limb insertions to tail base, mid-dorsal line confluent with central light spots; limbs with indistinct crossbars and a few lighter blotches; eight dark and seven light caudal bands, dark bands approximately twice as wide as light bands. 


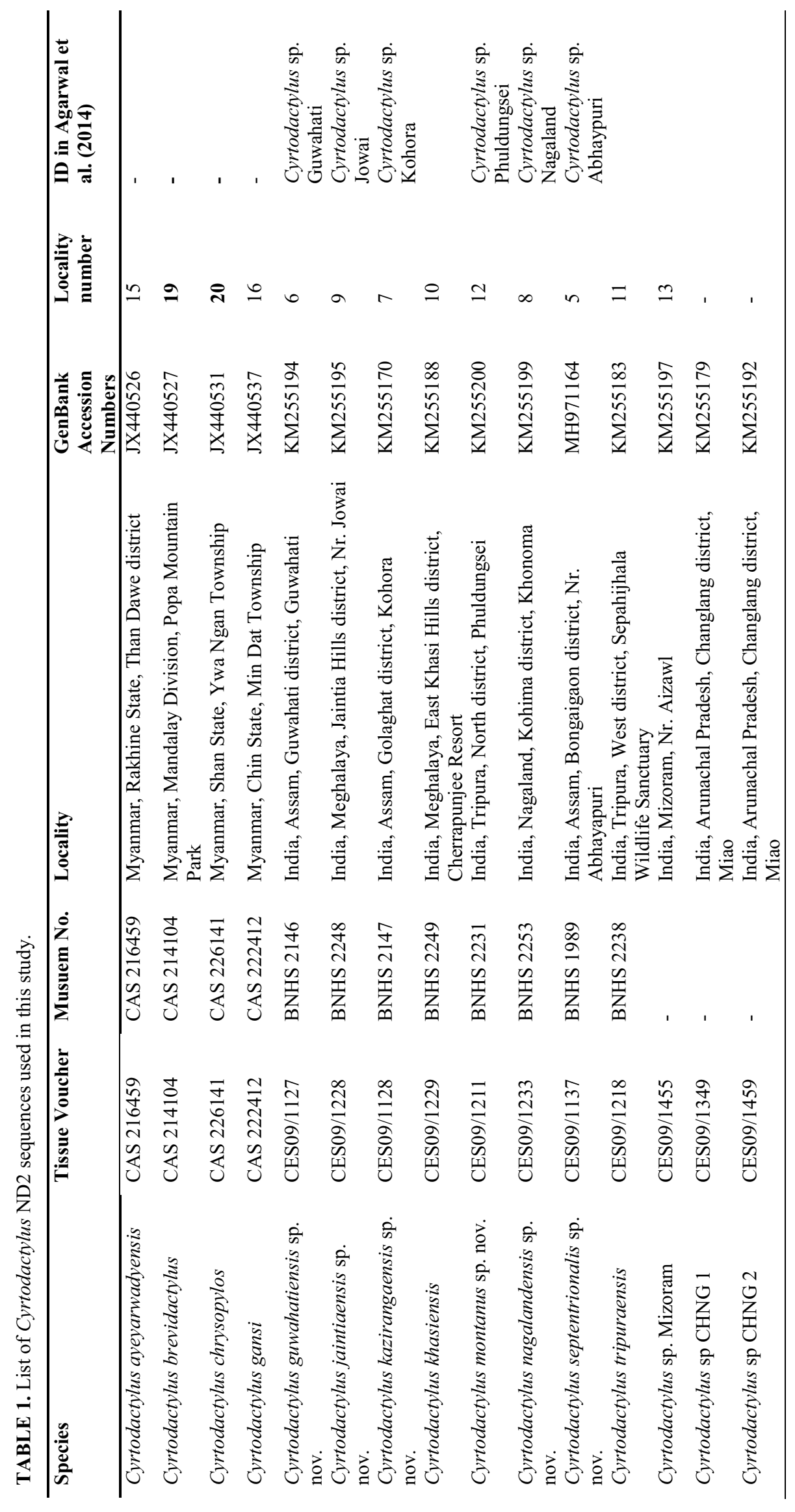




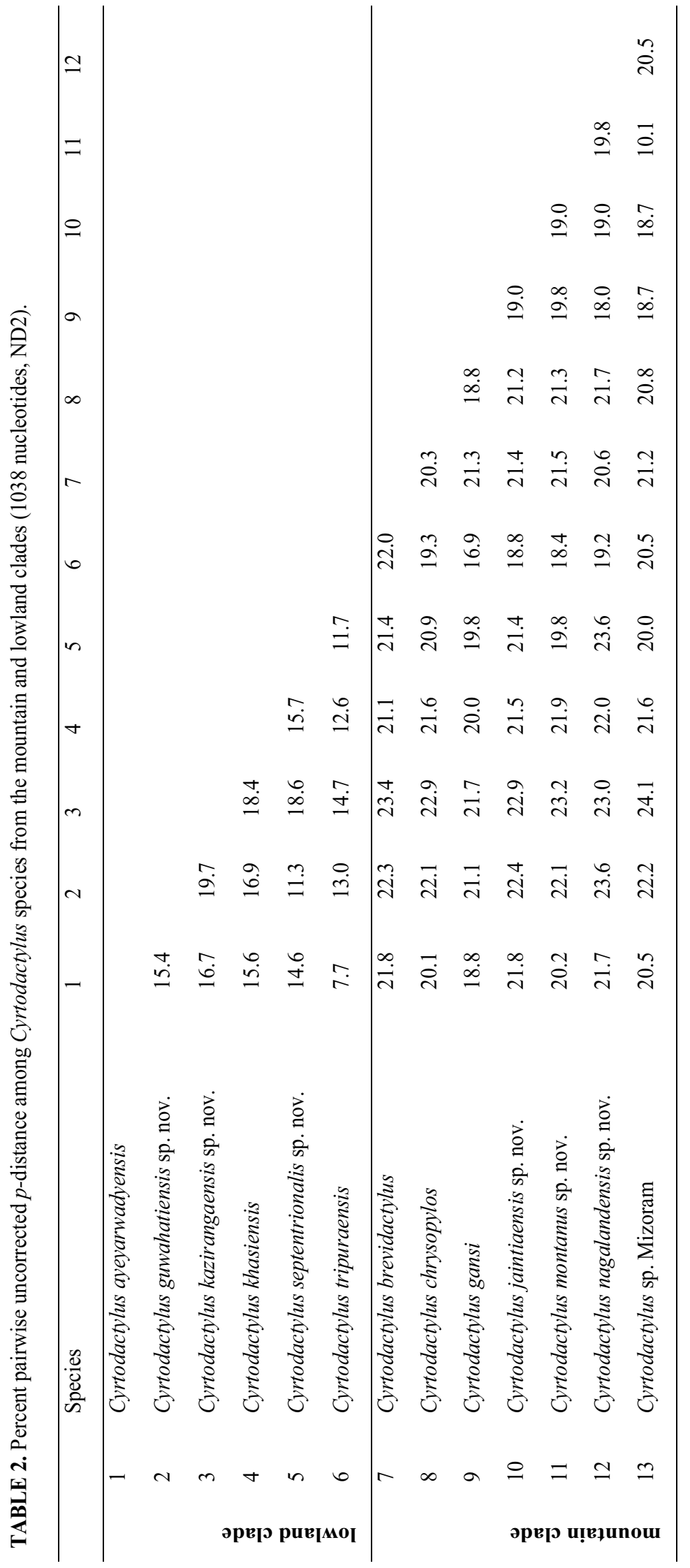




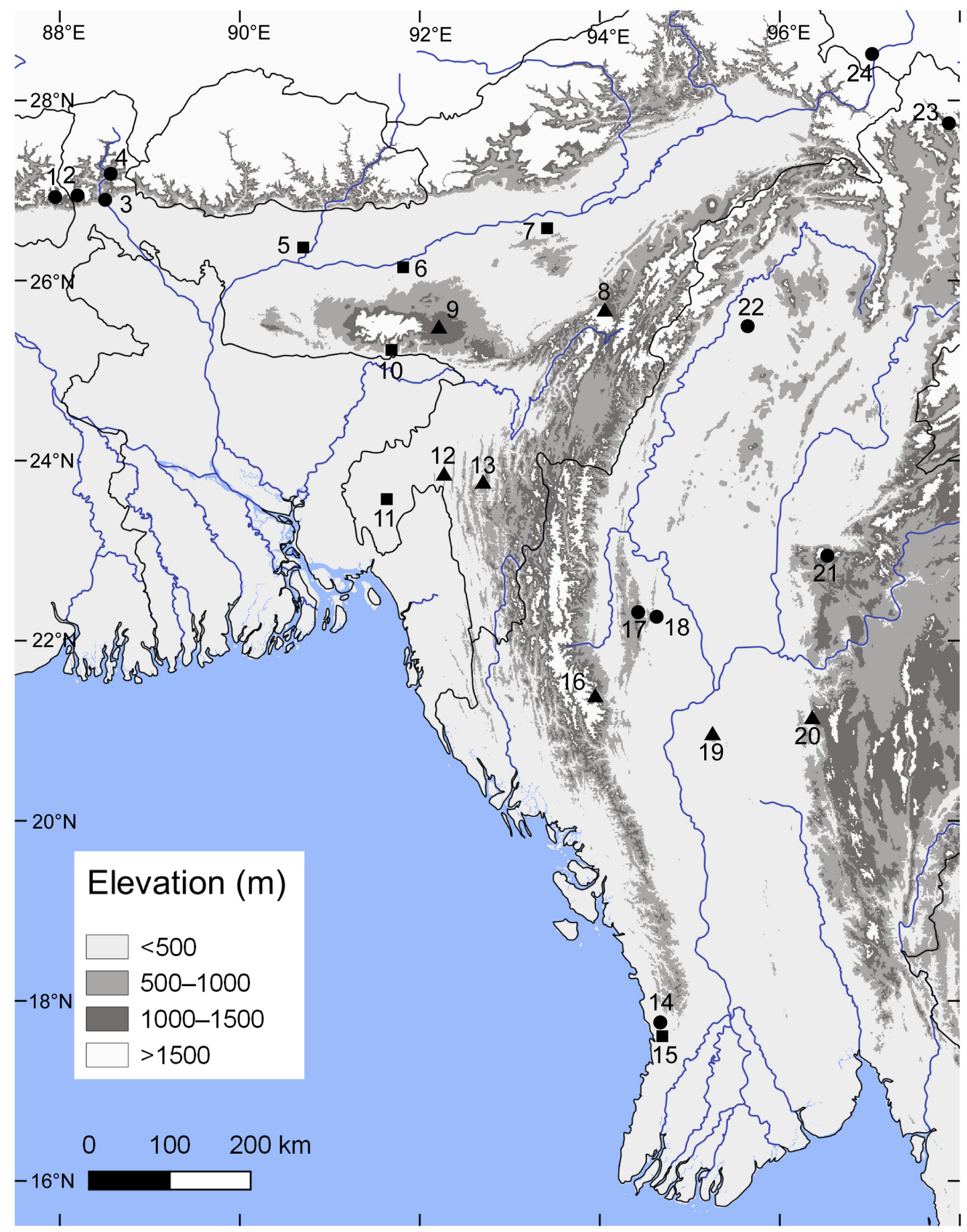

FIGURE 1. Elevation map of Indo-Burma showing the type localities of the new species and Cyrtodactylus species included in comparisons. Members of the mountain clade marked by triangles, the lowland clade by squares, and other species by circles. 1, Cyrtodactylus markuscombaii and C. martinstolli; 2, C. himalayicus; 3, C. bhupathyi; 4, C. gubernatoris; 5, C. septentrionalis sp. nov.; 6, C. guwahatiensis sp. nov.; 7, C. kazirangaensis sp. nov.; 8, C. nagalandensis sp. nov.; 9 , $C$. jaintiaensis sp. nov.; 10, C. khasiensis; 11, C. tripuraensis; 12, C. montanus sp. nov.; 13, C. sp. Mizoram; 14, C. wakeorum; 15, C. ayeyarwadyensis; 16, C. gansi; 17, C. slowinskii; 18, C. annandalei; 19, C. brevidactylus; 20, C. chrysopylos; 21, C. mandalayensis; 22, C. russelli; 23, C. tamaiensis; 24, C. cayuensis. Major rivers are labelled. 


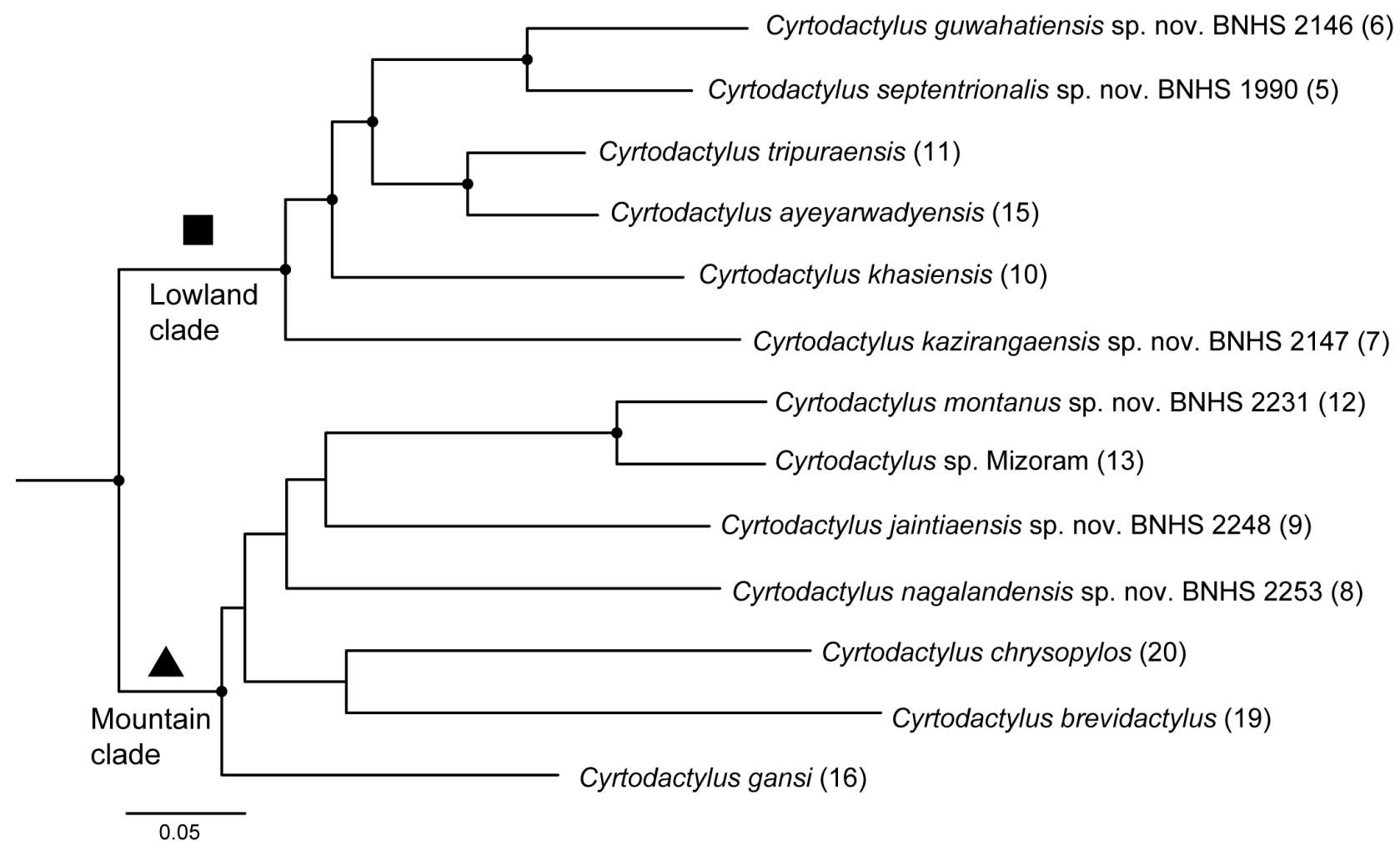

FIGURE 2. Maximum likelihood phylogeny showing relationships between the mountain and lowland clades (Agarwal et al. 2014). Numbers in parentheses reference localities in Figure 1 and Table 1, solid circles at nodes indicate bootstrap support $>75 \%$, outgroups not shown.

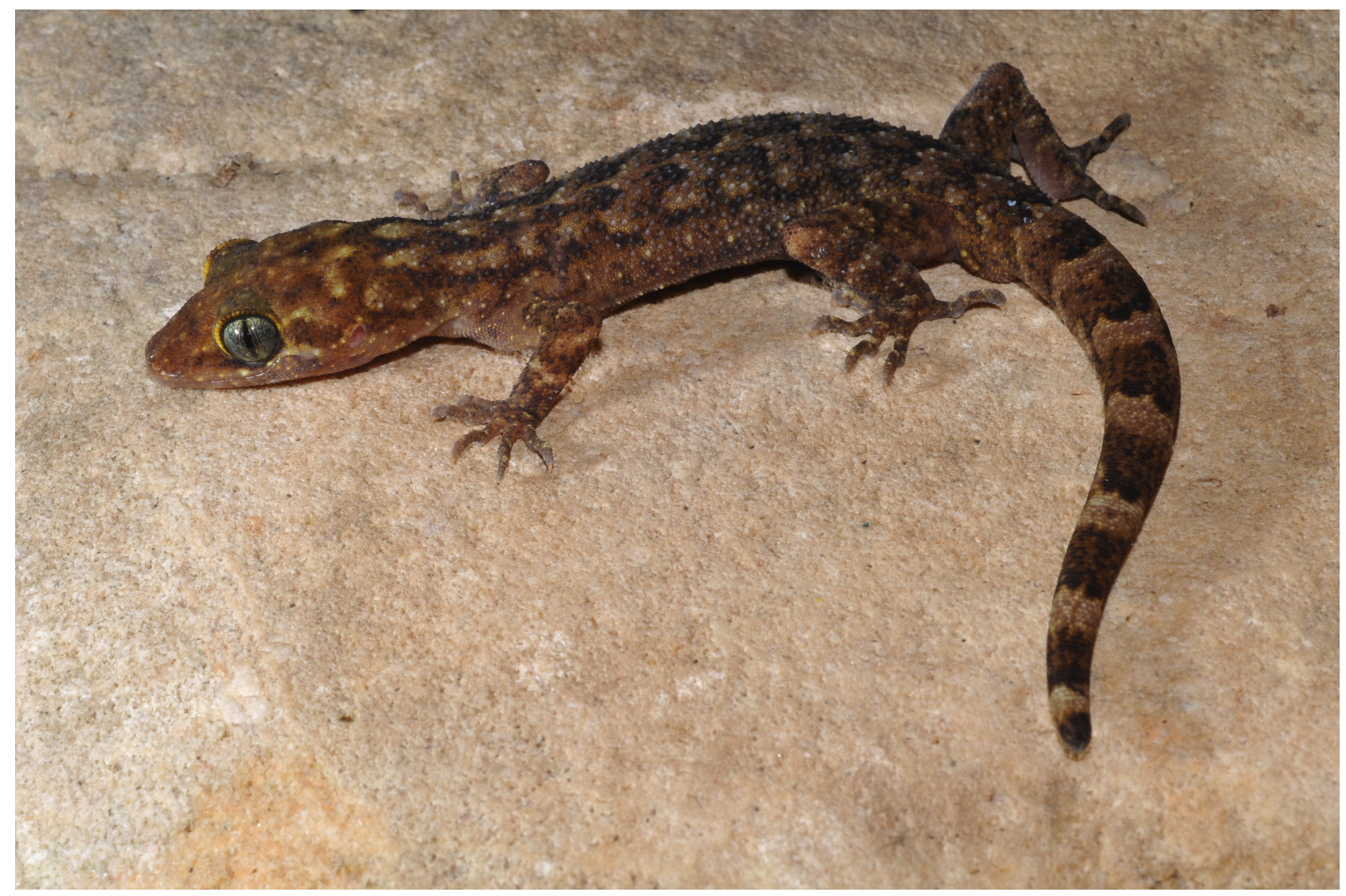

FIGURE 3. Cyrtodactylus guwahatiensis sp. nov. in life (adult male holotype, BNHS 2146). 

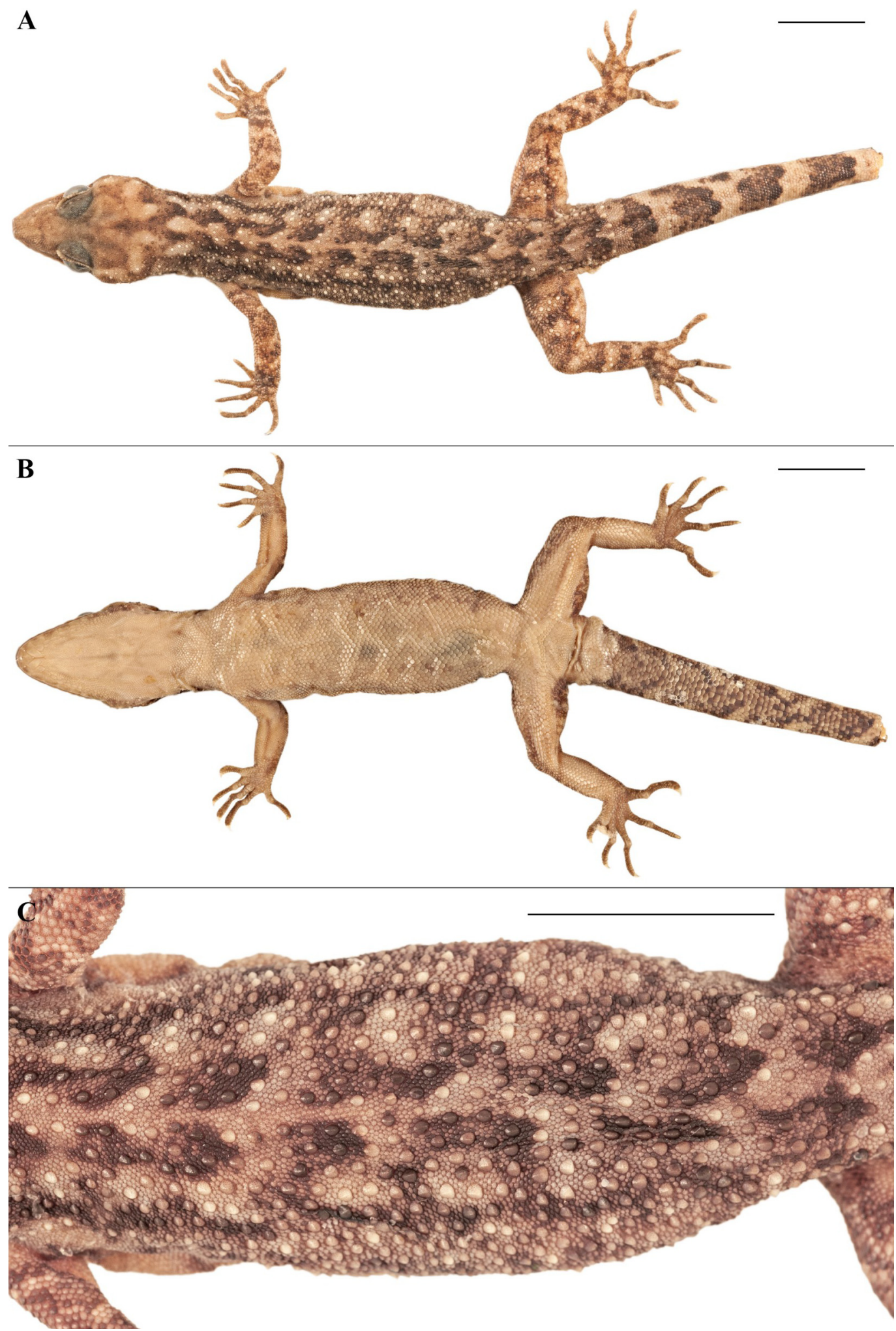

FIGURE 4. Dorsal view (A), ventral view (B), and details of dorsal pholidosis (C) of adult male holotype (BNHS 2146) of Cyrtodactylus guwahatiensis sp. nov. Scale bars $10 \mathrm{~mm}$.

Distribution and Natural History. This species is only known from a degraded moist deciduous forest on a small hill, completely surrounded by the urban sprawl of Guwahati, Assam. The holotype and only known specimen was collected near a seepage on a muddy wall along a hill road about 1.5 hours after sunset.

Comparisons. Cyrtodactylus guwahatiensis sp. nov. is a member of the lowland clade and is sister to $C$. septentrionalis sp. nov., the clade also including C. ayeyarwadyensis, C. tripuraensis, $C$. khasiensis and $C$. 
kazirangaensis sp. nov. The $p$-distance analysis demonstrated that the ND2 gene of the new species is $11.3 \%$ divergent from that of $C$. septentrionalis sp. nov. and 13.0-19.7\% divergent from others in the clade (Table 2). Cyrtodactylus guwahatiensis sp. nov. can be diagnosed by the total number of precloacofemoral pores (26 PcFP) on males from $C$. khasiensis (10-12 PcP) and C. tripuraensis (29-37 PcFP); further differs from C. tripuraensis by having slightly more DTR (23 or 24) and fewer MVSR (34) vs. (19-21 DTR, 35-43 MVSR). The new species differs in colouration from $C$. ayeyarwadyensis (no white punctuations or narrow band following dark dorsal markings) Cyrtodactylus guwahatiensis sp. nov. is diagnosed from $C$. kazirangaensis sp. nov. and $C$. septentrionalis sp. nov. after the descriptions of the latter two species. Major diagnostic characters for the new species and other regional congeners are summarized in Table 3.

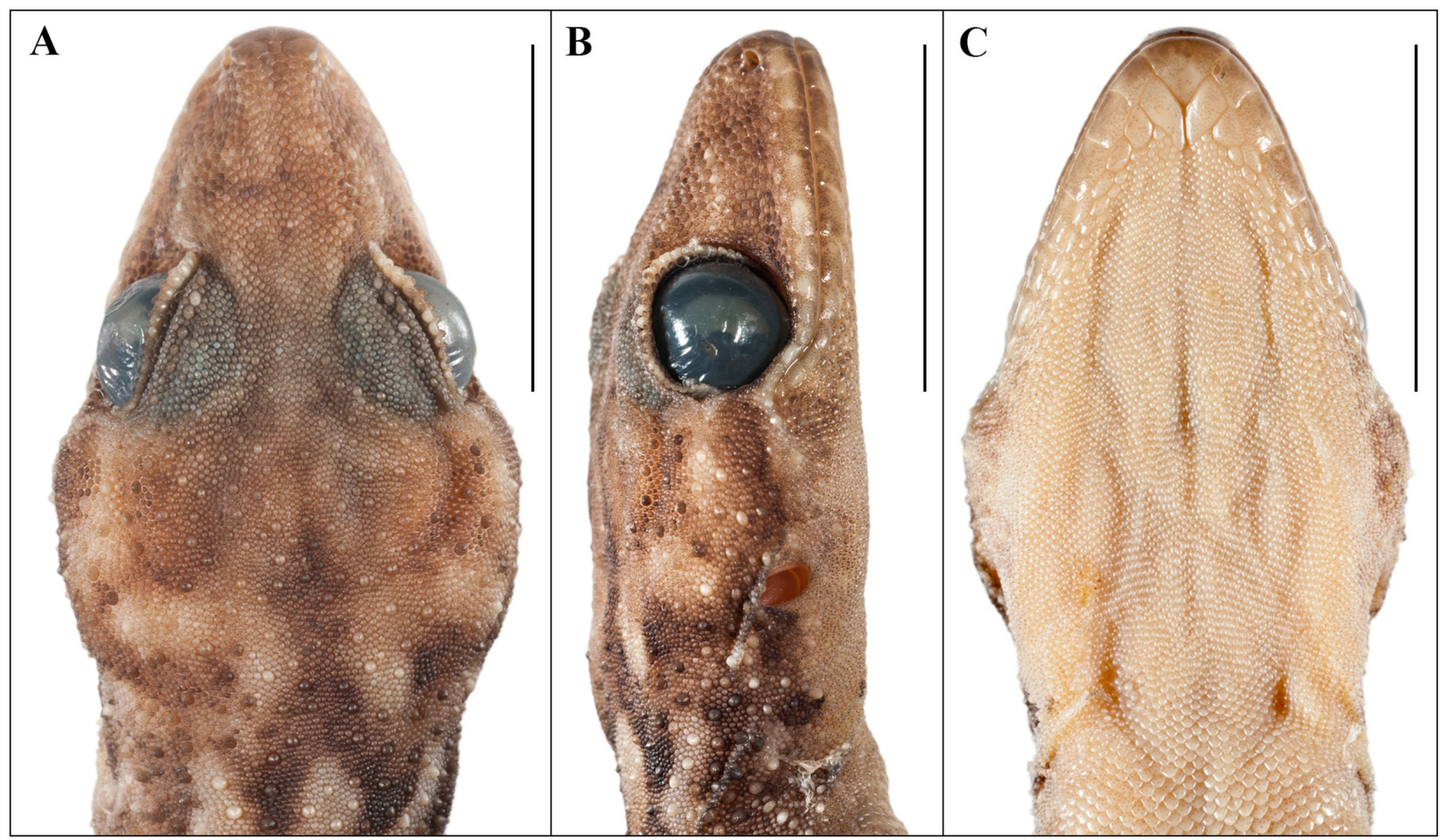

FIGURE 5. Head of Cyrtodactylus guwahatiensis sp. nov. (adult male holotype, BNHS 2146), dorsal (A), lateral (B), and ventral (C) view. Scale bars $10 \mathrm{~mm}$.

\section{Cyrtodactylus kazirangaensis sp. nov.}

Figs. 6-9.

Holotype. Adult male (BNHS 2148, field number CES09/1137) collected from near Hatikhuli Tea Estate, Golaghat district, Assam state, India $\left(26.57810^{\circ} \mathrm{N}, 93.40701^{\circ} \mathrm{E}, 100 \mathrm{~m}\right.$ asl.) by Ishan Agarwal on 11 November 2009.

Paratypes. Adult males (BNHS 2147, BNHS 2149) bear the same collection data as the holotype.

Etymology. The specific epithet is a toponym for Kaziranga National Park, which is adjacent to the type locality. Kaziranga, a World Heritage Site, is best known for having most of the world's surviving Indian onehorned rhinoceros, though it has high biodiversity across taxonomic groups.

Diagnosis. Cyrtodactylus kazirangaensis sp. nov. can be distinguished from all congeners by its moderate body size (SVL to at least $80.0 \mathrm{~mm}$ ); 11 or 12 supralabials; 9-11 infralabials; 22 or 23 longitudinal rows of rounded, feebly keeled dorsal tubercles; tubercles not extending beyond first segment of tail; 36-38 paravertebral tubercles; 37-43 ventral scales between ventrolateral folds; no precloacal groove; 10 or 11 precloacal pores and no femoral pores in males; $14-19$ total subdigital lamellae beneath toe IV of pes; subcaudal scalation of original tail without enlarged plates; dorsal pattern composed of six or seven irregular light and dark crossbars; tail with alternating dark and light bands. 


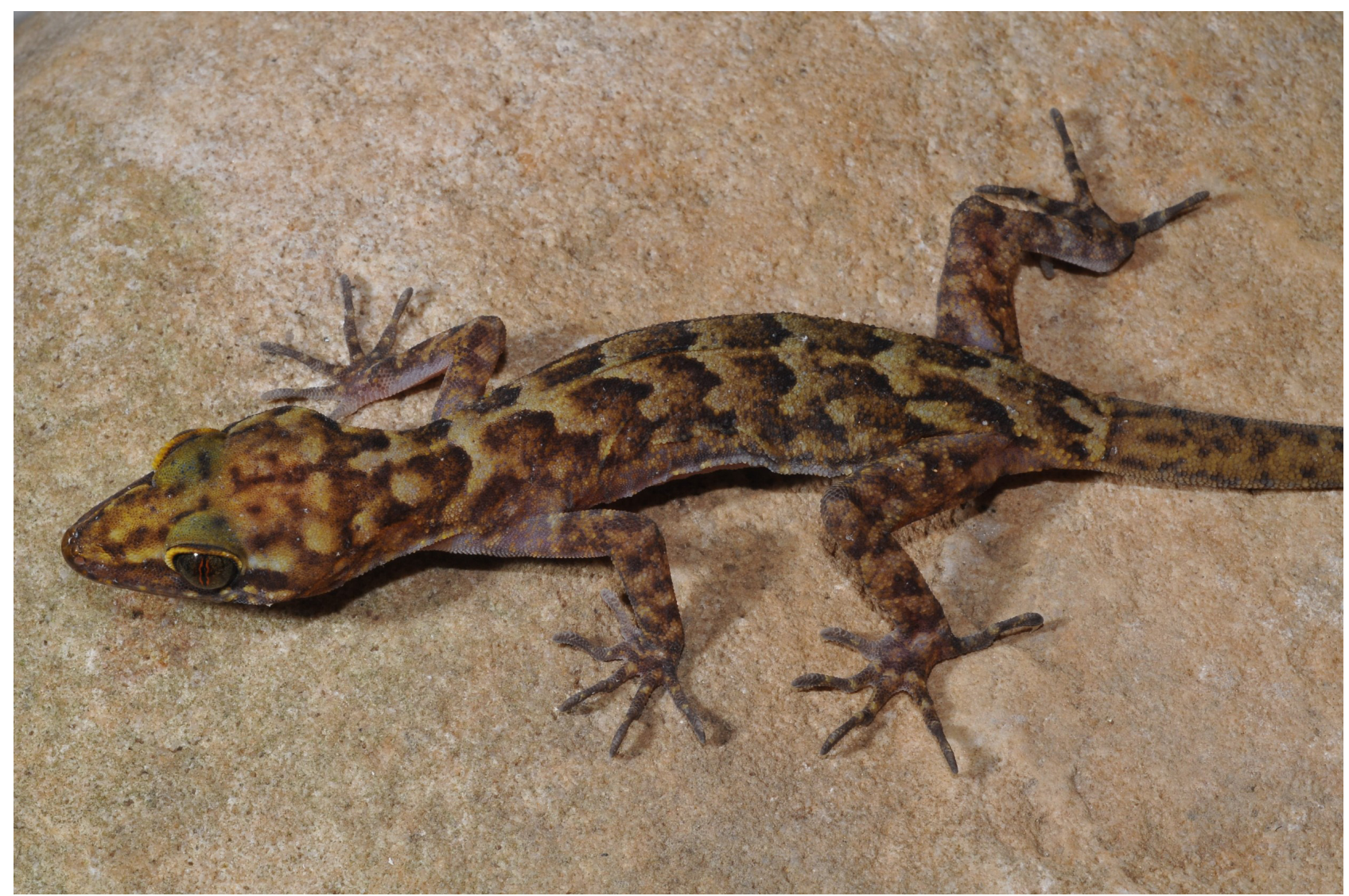

FIGURE 6. Cyrtodactylus kazirangaensis sp. nov. in life (adult male paratype BNHS 2149).

Description of holotype. Holotype in good preservation condition: tail curved toward left and tail tip removed as tissue voucher, fourth digit of right pes broken at inflection, constriction just anterior to hind limb insertion due to overzealous tag tying. Adult male, SVL $79.0 \mathrm{~mm}$. Head long (HL/SVL 0.27; HW/HL 0.69), somewhat depressed (HD/HW 0.55), distinct from neck; loreal region somewhat inflated, interorbital region flat, canthus rostralis not prominent; snout short (SE/HL 0.45), twice as long as orbital diameter (ED/SE 0.49); scales on snout and canthus rostralis granular, juxtaposed, homogenous in shape, with scales on snout being slightly larger; scales on interorbital region, dorsal surface of eyelids, forehead and occipital region slightly smaller, granular, juxtaposed, with those on forehead and interorbital region interspersed with slightly larger tubercles that are rounded, smooth and two to three times the size of adjacent granules; enlarged tubercles sparse on forehead and dense on occipital region. Eye small (ED/HL 0.22); pupil vertical with crenulated margins; supraciliaries large, decreasing in size towards posterior and anterior ends of orbit, largest about one-third the way from anterior edge of orbit; dorsal surface of eyelids covered with granular scales, row of tubercles bordering supraciliaries absent. Ear opening oval, obliquely oriented, large; eye to ear distance slightly more than eye diameter (ED/EE 0.73). Rostral much wider $(3.2 \mathrm{~mm})$ than deep $(1.4 \mathrm{~mm})$, partially divided dorsally by weakly developed rostral groove; single much enlarged supranasal on either side, separated by one slightly smaller, circular internasal, which is twice the size of enlarged scales on snout; rostral in contact with supralabial I, nostrils, supranasals and internasals; nostrils oval, laterally oriented, posterior half covered by a nasal pad, each in broad contact with rostral and surrounded by supranasal, supralabial I, and four smaller, granular postnasal scales; seven rows of granular scales between midorbital position and supralabials; mental wider $(2.8 \mathrm{~mm})$ than deep $(2.0 \mathrm{~mm})$, triangular, two well-developed postmentals on either side, inner pair in broad contact $(1.5 \mathrm{~mm})$ behind mental, larger $(2.2 \mathrm{~mm})$ than and separating outer pair $(1.3 \mathrm{~mm})$; each inner postmental bordered by mental, infralabial I, outer postmental and two enlarged gular scales; outer postmentals bordered by inner postmentals, infralabials I and II, a large, roughly hexagonal scale posteriorly and four gular scales; eight supralabials to midorbital position and 12 to angle of jaw on each side, bordered by a row of flat, somewhat elongated scales, slightly larger than their adjacent granules; 10 infralabials on each side. 

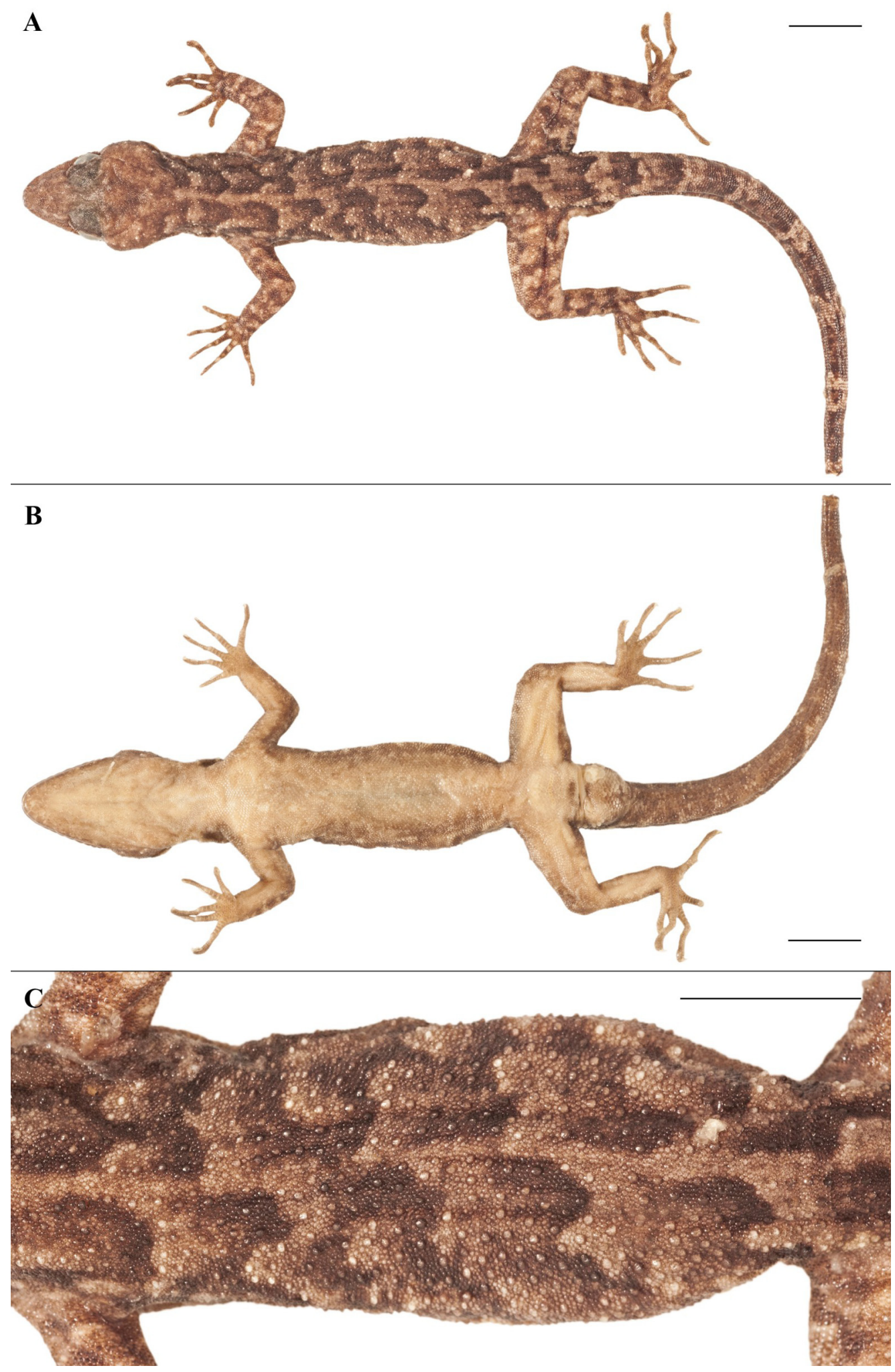

FIGURE 7. Dorsal view (A), ventral view (B), and details of dorsal pholidosis (C) of adult male holotype (BNHS 2148) of Cyrtodactylus kazirangaensis sp. nov. Scale bars $10 \mathrm{~mm}$.

Body slender (BW/TRL 0.42), short (TRL/SVL 0.44); dorsal scales heterogeneous, mostly rounded granules, intermixed with irregularly arranged enlarged tubercles that are rounded and feebly keeled, flatter and more strongly keeled towards vertebral region; tubercles extend from forehead posteriorly onto base of tail; tubercles on nape smaller than those of dorsum; 22 dorsal tubercles across mid dorsum; 36-38 paravertebral tubercles; ventrolateral folds covered by scattered enlarged, smooth scales; ventral scales much larger than dorsals, smooth, 
rounded, juxtaposed; smaller under thighs; two rows of enlarged subimbricate scales along posterior border of precloacal pores; 39 or 40 ventral scales between ventrolateral folds; gular region with much smaller granular scales throughout, except two rows of larger, flat, juxtaposed scales originating from the posterior margin of the outer postmentals and bordering infralabials. Eleven precloacal pores in a continuous series; femoral pores absent; no precloacal groove; hemipenal bulge distinct.

Fore and hind limbs slender; forearm (FL/SVL 0.15) and tibia (CL/SVL 0.17) short; digits short, strongly inflected at each joint, all bearing robust recurved claws; five subdigital lamellae in basal series and 10 in distal series with four non-lamellar granules at inflection (digit IV, right manus); eight basal and 11 distal lamellae with four non-lamellar granules at inflection (digit IV, right pes); inter-digital webbing absent on manus, rudimentary between toes I to IV; relative length of digits: I $<$ II $<$ V $<$ III $<$ IV (left manus) and I $<$ II $<$ V $<$ III $<$ IV (left pes); scales on palms and soles smooth, flat, juxtaposed; scales on fore limbs heterogeneous, composed of rounded, granular, juxtaposed scales on upper arms, those on forearms heterogeneous, granular, becoming flat, smooth and subimbricate anteriorly, sparsely interspersed with slightly enlarged rounded tubercles; ventral portion covered mostly with flat, granular, juxtaposed scales; scales on hind limbs heterogeneous, dorsal part of thighs and shanks, with small, slightly pointed granular scales, intermixed with scattered, enlarged, rounded tubercles; ventral aspect of hind limbs with enlarged, smooth, subimbricate scales.

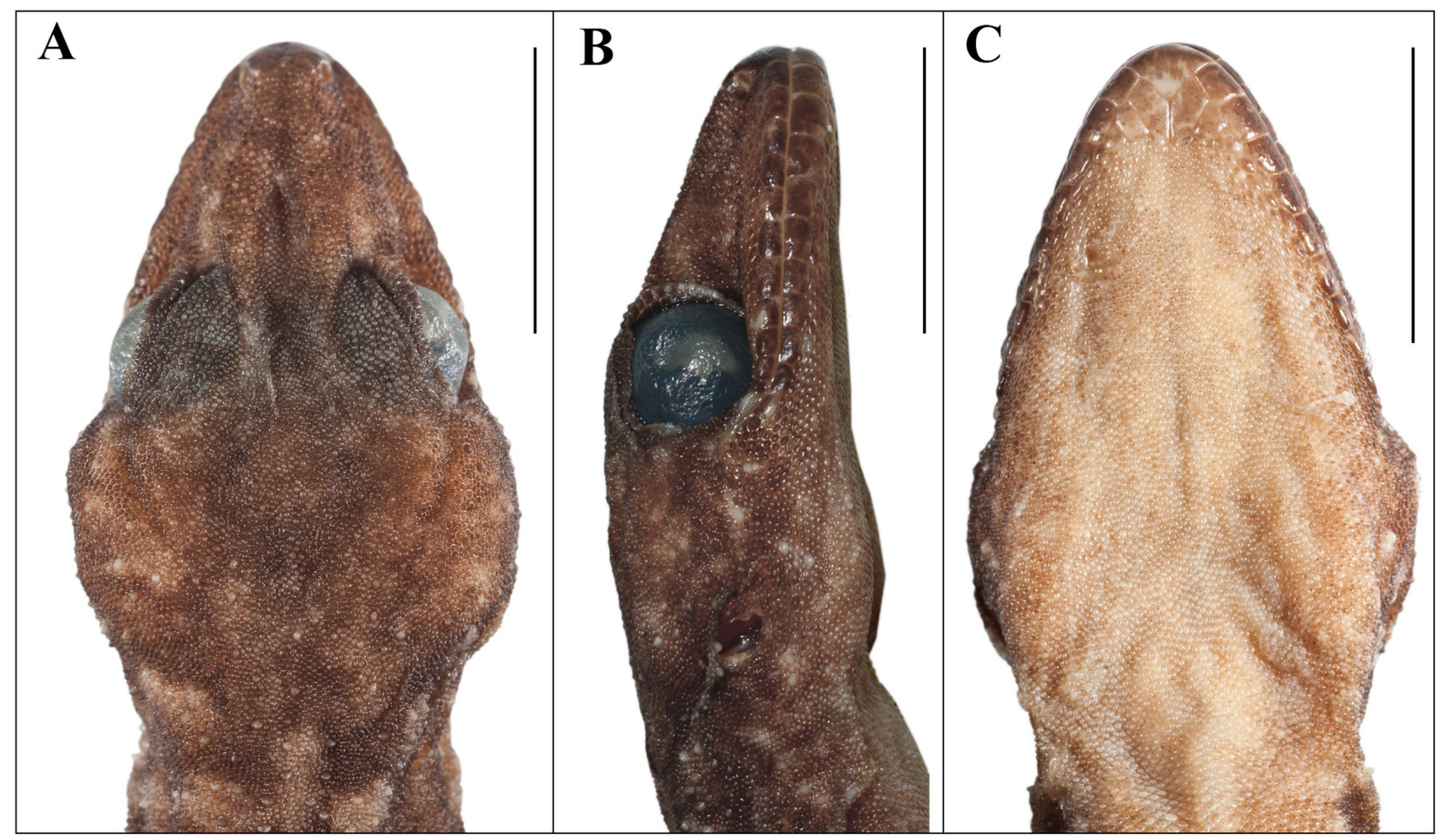

FIGURE 8. Head of Cyrtodactylus kazirangaensis sp. nov. (adult male holotype, BNHS 2148), dorsal (A), lateral (B), and ventral (C) view. Scale bars $10 \mathrm{~mm}$.

Tail original, tip missing, somewhat rounded, slender, tapering, divided into indistinct segments; six or seven rows of enlarged, flat, weakly pointed, feebly keeled, tubercles on base and first segment of tail only, remaining dorsal caudal scales smooth, rounded, subimbricate, similar in size dorsally but becoming larger on lateral aspect; subcaudal scales larger, smooth, imbricate; with no distinct mid-ventral series of paired scales. Five enlarged, smooth post cloacal spurs on each side.

Colouration in life (for paratype BNHS 2149, Fig. 6). Dorsal ground colour of body, limbs and tail brown; top of head pale brown with scattered dark brown streaks; labials darker than dorsum of head; a preorbital streak and two light yellow narrow postorbital streaks that do not extend as far as ear opening; occiput with light yellowbuff blotches; neck with light tan blotches forming indistinct wavy cross-bar flanked by a pair of dark blotches, light mid-dorsal marking extends from occiput to tail base, seven light and seven dark bands from fore limb insertion to tail base; ventral surfaces immaculate; limbs with indistinct crossbars and a few lighter blotches; 
regenerated tail light brown with dark spots dorsally, light grey and tan ventrally; iris green-brown with darker reticulations, pupil outlined in orange-red

Colouration in preservative (Figs. 7 \& 8). Dorsal ground colour of body, limbs and tail brown; top of head mottled brown; labials about as dark as dorsum of head; two indistinct light narrow postorbital streaks that do not extend as far as ear opening, preorbital streak indistinct; occiput with light blotches; neck with light tan blotches forming indistinct cross-shaped marking bar flanked by a pair of dark blotches, light mid-dorsal marking discontinuous from occiput to tail base, seven light and seven dark bands from fore limb insertion to tail base; ventral surfaces immaculate; limbs with indistinct crossbars and a few lighter blotches; regenerated tail light brown with dark spots dorsally, light grey and tan ventrally.

Variation (Fig. 9). Dorsal colour pattern of six or seven irregular light and dark crossbars on types; BNHS 2147 darker in ground colouration, without clear mid-dorsal markings; crown-shaped light marking on nape; regenerated portion of tail dirty brown; ventral surfaces dirty white, subcaudals dark with some lighter, and yellow spots. Both paratypes have a continuous series of 10 precloacal pores (Table 4).

Distribution and Natural History. Cyrtodactylus kazirangaensis sp. nov.is known only from its type locality, which lies at the northern edge of the Mikir Hills. The entrance to Kaziranga National Park is less than $5 \mathrm{~km}$ away, and it is likely that this species also occurs in the park itself. The type series was collected together emerging from drainage holes in a concrete wall on the edge of a patch of degraded deciduous forest/plantations, facing a small stream, about an hour after sunset.

Comparisons. Cyrtodactylus kazirangaensis sp. nov. is a member of the lowland clade and differs from other species by 14.7-19.7\% uncorrected genetic distance. Cyrtodactylus kazirangaensis sp. nov. can be diagnosed by the presence of 10 or 11 precloacal pores and absence of femoral pores on males from C. ayeyarwadyensis (10-28 PcP-PcFP), Cyrtodactylus guwahatiensis sp. nov. (26 PcFPs in a discontinuous series), and C. tripuraensis (29-37 PcFP). Cyrtodactylus kazirangaensis sp. nov. can be further diagnosed by having more ventral scales (37-43 MVSR) than C. ayeyarwadyensis (32-37 MVSR). Cyrtodactylus kazirangaensis sp. nov. is very similar morphologically to $C$. khasiensis from which it differs in the ear to eye distance being proportionately less than snout to eye distance (EE/SE $0.67-0.69 \mathrm{vs.} 0.70-0.77$ ), and ear to eye distance proportionately less than nostril to eye distance (EE/NE 0.81-0.88 vs. 0.90-1.01). Cyrtodactylus kazirangaensis sp. nov. is diagnosed against $C$. septentrionalis sp. nov. after its description. Major diagnostic characters for the new species and other regional congeners are summarized in Table 3.

Remarks. Wood et al. (2012) included a specimen of C. "khasiensis" (MFA 50083) from "Kaziranga, Assam" and the ND2 sequence (JX440543) was found to be 99\% similar to the sequence (KM255170) of the paratype of Cyrtodactylus kazirangaensis sp. nov. in a BLAST search (results not shown), and thus is referable to this species. This sequence was also included in Brennan et al's (2017) phylogenetic study as C. "khasiensis".

\section{Cyrtodactylus septentrionalis sp. nov.}

Figs. 9-11.

Holotype. Adult female (BNHS 1990), collected from near Abhayapuri town, Bongaigaon district, Assam state, India $\left(26.345417^{\circ} \mathrm{N}, 90.677875^{\circ} \mathrm{E}, 40 \mathrm{~m}\right.$ asl.) by Varad Giri and Kedar Bhide on 13 November 2009.

Paratype. Adult male (BNHS 1989), bears the same collection details as holotype.

Etymology. The specific epithet is a nominative, masculine, singular, Latin adjective meaning "northern", as this species is the only known member of the lowland clade (Agarwal et al. 2014) that is found north of the Brahmaputra River, the other five known species of the clade are found south of the Brahmaputra River.

Diagnosis. Cyrtodactylus septentrionalis sp. nov. can be distinguished from all congeners by its moderate body size (SVL to at least $65.2 \mathrm{~mm}$ ); nine or 10 supralabials; nine infralabials; 23 or 24 longitudinal rows of bluntly conical, feebly keeled dorsal tubercles; tubercles extend onto first three tail segments; $38-42$ paravertebral tubercles; 35-38 ventral scales between ventrolateral folds; no precloacal groove; 14 fine precloacal pores and no femoral pores on males; 15-20 total subdigital lamellae beneath toe IV of pes; subcaudal scalation of original tail without enlarged plates; dorsal colour pattern of 6-9 rows of paired dark blotches, tail with alternating dark and lighter bands.

Description of holotype. Holotype generally in good preservation condition: trunk curved to left, folds of skin 
along either side of ventrolateral aspect, constriction just anterior to hind limb insertion due to overzealous tag tying. Adult female, SVL $65.2 \mathrm{~mm}$. Head long (HL/SVL 0.30), slightly wide (HW/HL 0.70), not depressed (HD/ HW 0.63), distinct from neck; loreal region somewhat inflated, interorbital region flat, canthus rostralis not prominent; snout short (SE/HL 0.50), twice as long as orbital diameter (ED/SE 0.50); scales on snout and canthus rostralis granular, juxtaposed, homogenous in shape with scales on dorsum of snout being slightly larger; scales on interorbital region, forehead and occipital region slightly smaller, granular, juxtaposed; forehead sparsely and occipital region densely interspersed with larger tubercles that are rounded, smooth, and two times the size of adjacent granules. Eye small (ED/HL 0.20); pupil vertical with crenulated margins; supraciliaries flat, smooth, roughly triangular, decreasing in size towards posterior and anterior ends of orbit, largest about one-third the way from anterior edge of orbit; a single row of enlarged tubercles bordering supraciliaries present on dorsal surface of upper eyelid. Ear opening oval, obliquely oriented, large. Eye to ear distance slightly larger than diameter of eye (ED/EE 0.70$)$. Rostral wider $(2.7 \mathrm{~mm})$ than deep $(1.7 \mathrm{~mm})$, divided dorsally by a weakly developed rostral groove; single much enlarged rounded supranasal on either side, separated by two rows of three granular scales; rostral in contact with supralabials I, nostrils, supranasals and three scales separating supranasals; nostrils oval, laterally oriented, posterior half covered by a conspicuous nasal pad, each nostril in broad contact with rostral and surrounded by internasal, supralabial I, and four smaller, granular postnasal scales; three rows of granular scales separate orbit from supralabials; mental wider $(2.3 \mathrm{~mm})$ than deep $(2.0 \mathrm{~mm})$ triangular, two well-developed pairs of postmentals on either side, inner pair in broad contact $(1.2 \mathrm{~mm})$ behind mental, twice the size $(2.1 \mathrm{~mm})$ of and separating outer pair $(1.0 \mathrm{~mm})$; each inner postmental bordered by mental, infralabial I, outer postmental and three gular scales, outermost of which is largest; outer postmentals bordered by inner postmentals, infralabials I and II, a large, roughly hexagonal scale posteriorly and four gular scales; seven supralabials to midorbital position on each side; supralabials to angle of jaw, nine on right side and 10 on left side, bordered by a row of flat, somewhat elongated scales slightly larger than adjacent granular scales; nine infralabials on each side, infralabials II-V bordered by one or two rows of enlarged scales, anteriormost largest.

Body slender (BW/TRL 0.4), short (TRL/SVL 0.40); dorsal scales heterogeneous with mostly rounded granules intermixed with irregularly arranged, enlarged tubercles that are rounded, slightly conical, feebly keeled; a distinct ventrolateral fold on either side with enlarged, rounded, flat tubercles interspersed by one or two slightly enlarged, flat, juxtaposed scales; tubercles extend from forehead posteriorly onto base of tail; tubercles on nape smaller than those of dorsum; 23 or 24 dorsal tubercles across mid-dorsum; 38 paravertebral tubercles; ventral scales much larger than dorsals, smooth, cycloid, juxtaposed; slightly smaller in size under thighs; a row of slightly enlarged, flat, subimbricate scales along posterior border of precloacal scales; 36-38 ventral scales between ventrolateral folds; gular region with small granular scales throughout, except for one or two rows originating from posterior margin of outer postmentals, bordering infralabials, which are larger, flat, juxtaposed. A continuous series of 14 indistinct depressions in precloacal scales, no pores, no precloacal groove.

Fore and hind limbs slender; forearm (FL/SVL 0.20) and tibia (CL/SVL 0.20) short; digits short, strongly inflected at each joint, all bearing robust recurved claws that are slightly longer than claw sheath; six subdigital lamellae in basal series and nine in distal series with three non-lamellar granules at inflection (digit IV, right manus); five basal and 10 distal lamellae with four non-lamellar granules at inflection (digit IV, right pes); slight inter-digital webbing between toes I-III, absent between fingers; relative length of digits: I $<$ II $<$ V $<$ III $<$ IV (right manus) and I $<$ II $<$ III $<$ V $<$ IV (right pes); scales on palms and soles smooth, flat, juxtaposed, with those on sole being slightly larger; scales on fore limbs heterogeneous, composed of large, granular, juxtaposed scales becoming flatter, smooth and subimbricate anteriorly, sparsely interspersed with slightly enlarged rounded, feebly keeled tubercles; ventral portion covered mostly with granular, rounded, juxtaposed scales; scales on hind limbs heterogeneous, with large, subimbricate, flat scales, scattered densely with rounded, enlarged, conical, strongly keeled tubercles; ventral aspect of hind limbs with enlarged, smooth, subimbricate scales.

Tail original with regenerated tip, somewhat rounded, slender, tapering, not divided into segments; about ten rows of enlarged, rounded, feebly keeled tubercles on tail base and 1-4 rows on the first three segments; remaining dorsal caudal scales smooth, roughly rectangular, subimbricate throughout without a single row of tubercles along the posterior edge of the first three segments; subcaudal scales larger, smooth, imbricate; no distinct mid-ventral series; three enlarged smooth post cloacal spurs on each side.

Colouration in life. Not documented.

Colouration in preservative (Figs. 10 \& 11). Dorsal ground colour of body, head, limbs and tail light brown; 
top of head scattered with few dark brown markings including longitudinal streak extending from occiput to nape; labials pale cream with fine black stippling; dark postorbital streak flanked by lighter markings that extend to ear openings, dark preorbital streak present extending to nostrils; neck with three longitudinal dark markings; dorsal pattern of six or seven pairs of dark elongated blotches from fore limb insertion to tail base; ventral surfaces immaculate; limbs with dark blotches; original portion of tail with eight dark and light markings that circle tail; regenerated portion of tail light brown, with a few dark spots.

Variation (Fig. 9). BNHS 1989 is a male with 13 fine precloacal pores and nine pairs of dark dorsal markings; six dark and light markings on incomplete but original tail; broadly agreeing in scalation with the holotype (Table 4).

Distribution and Natural History. Cyrtodactylus septentrionalis sp. nov. is only known from the vicinity of Abhayapuri town, close to the base of Bamun Gaon Pahar (a small hill). Nine individuals of this species were observed during a single night of search. They were found on open rocks along a small stream running through degraded forest near a human settlement.
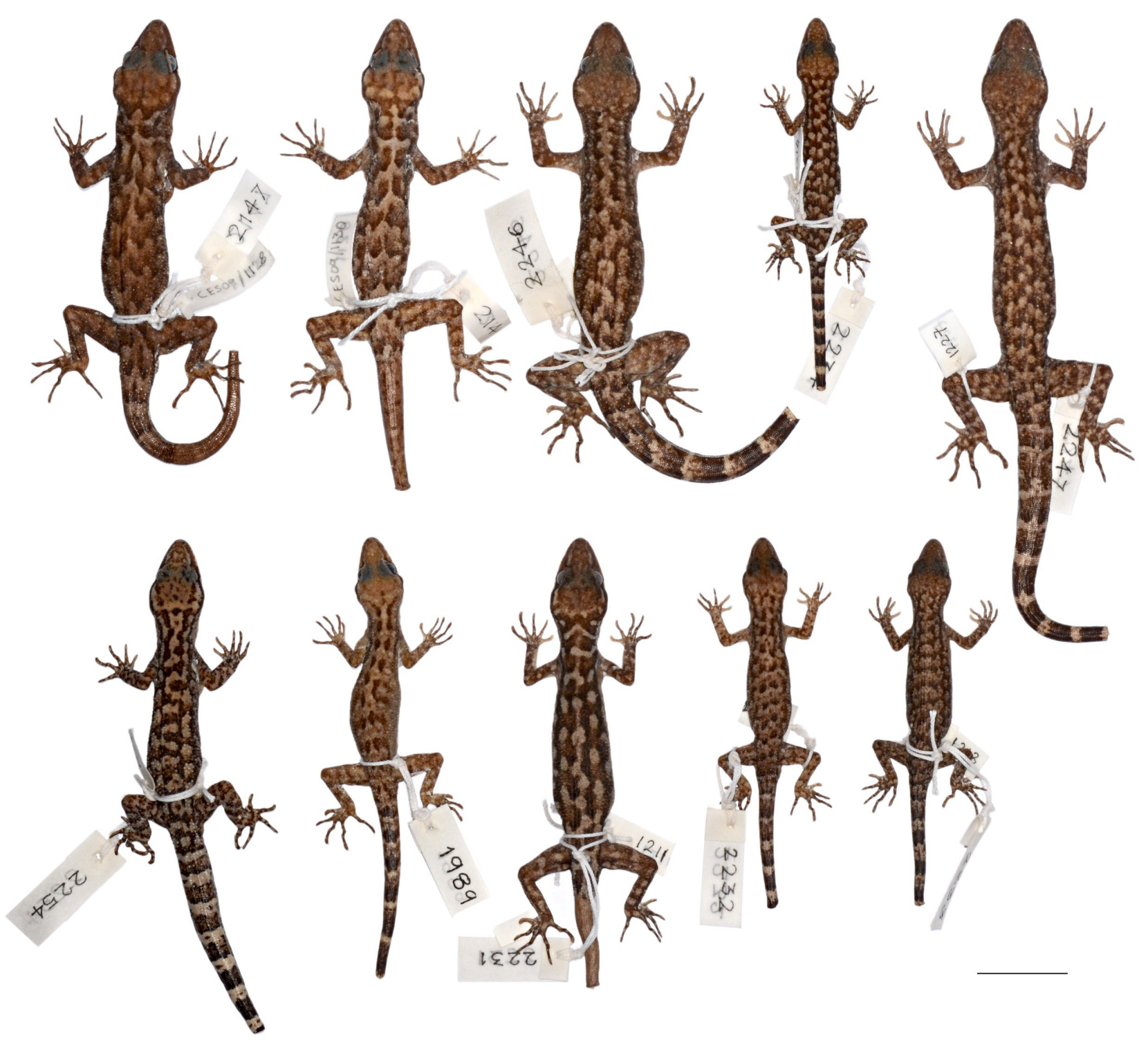

FIGURE 9. Paratypes of the new species described in this paper. From left to right, top panel: Cyrtodactylus kazirangaensis sp. nov. (BNHS 2147, 2149), Cyrtodactylus jaintiaensis sp. nov. (BNHS 2246), Cyrtodactylus montanus sp. nov. (BNHS 2234), and Cyrtodactylus jaintiaensis sp. nov. (BNHS 2247); bottom panel: Cyrtodactylus nagalandensis sp. nov. (BNHS 2254), Cyrtodactylus septentrionalis sp. nov. (BNHS 1989), and Cyrtodactylus montanus sp. nov. (BNHS 2231-2233). 


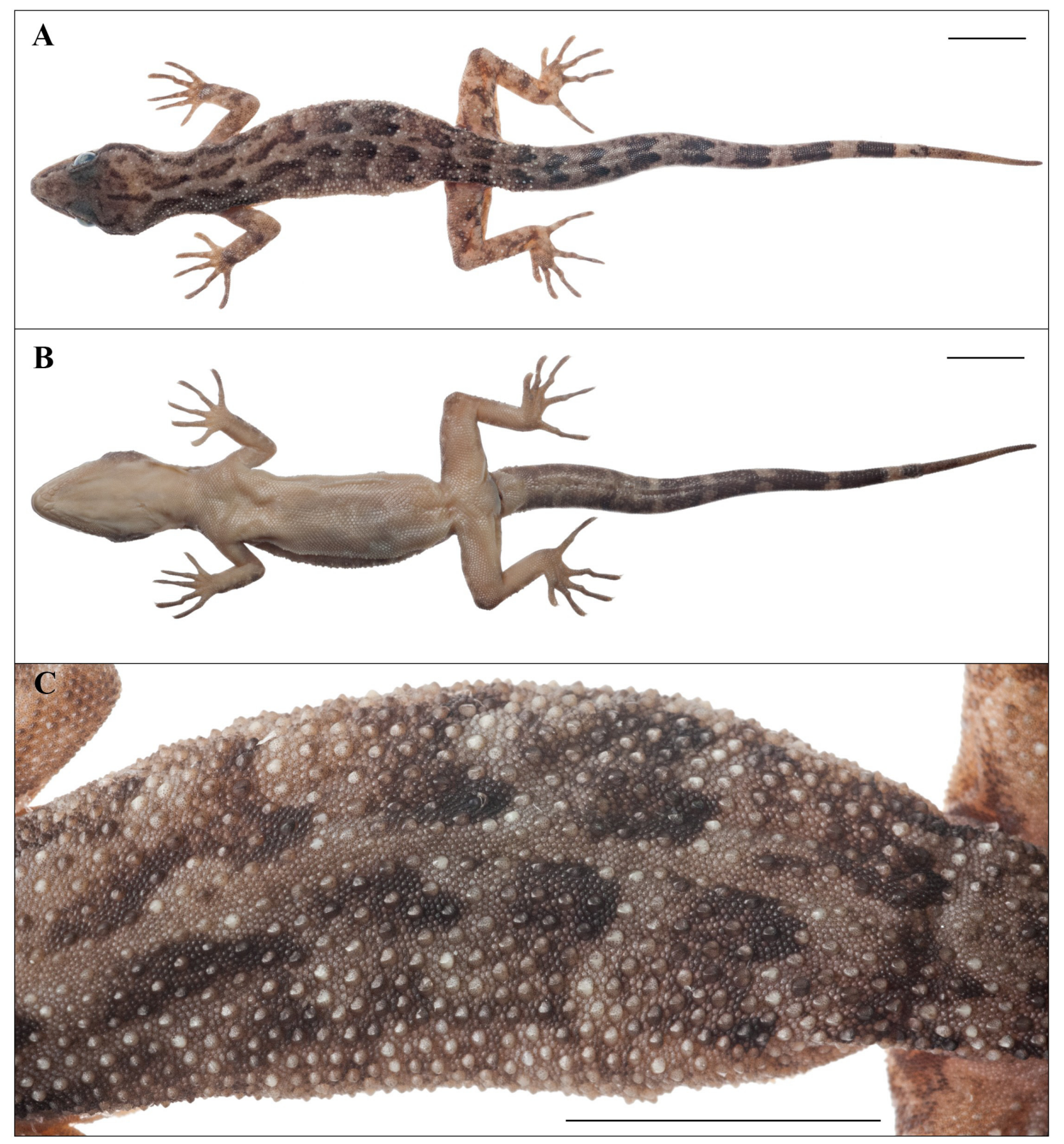

FIGURE 10. Dorsal view (A), ventral view (B), and details of dorsal pholidosis (C) of adult female holotype (BNHS 1990) of Cyrtodactylus septentrionalis sp. nov. Scale bars $10 \mathrm{~mm}$.

Comparisons. Cyrtodactylus septentrionalis sp. nov. is a member of the lowland clade and differs from other members of the clade by $11.3-18.6 \%$ uncorrected genetic distance. Cyrtodactylus septentrionalis sp. nov. can be diagnosed by the presence of 14 precloacal pores and the absence of femoral pores on males from $C$. ayeyarwadyensis (10-28 PcP-PcFP), Cyrtodactylus guwahatiensis sp. nov. (26 PcFP in discontinuous series), Cyrtodactylus kazirangaensis sp. nov. (10 or $11 \mathrm{PcP})$, C. khasiensis (10-12 PcP), and C. tripuraensis (29-37 PcFP). Cyrtodactylus septentrionalis sp. nov. further differs from $C$. khasiensis in having more dorsal tubercle rows (23 or 24 vs. 19-23). Major diagnostic characters for the new species and regional congeners are summarized in Table 3. 


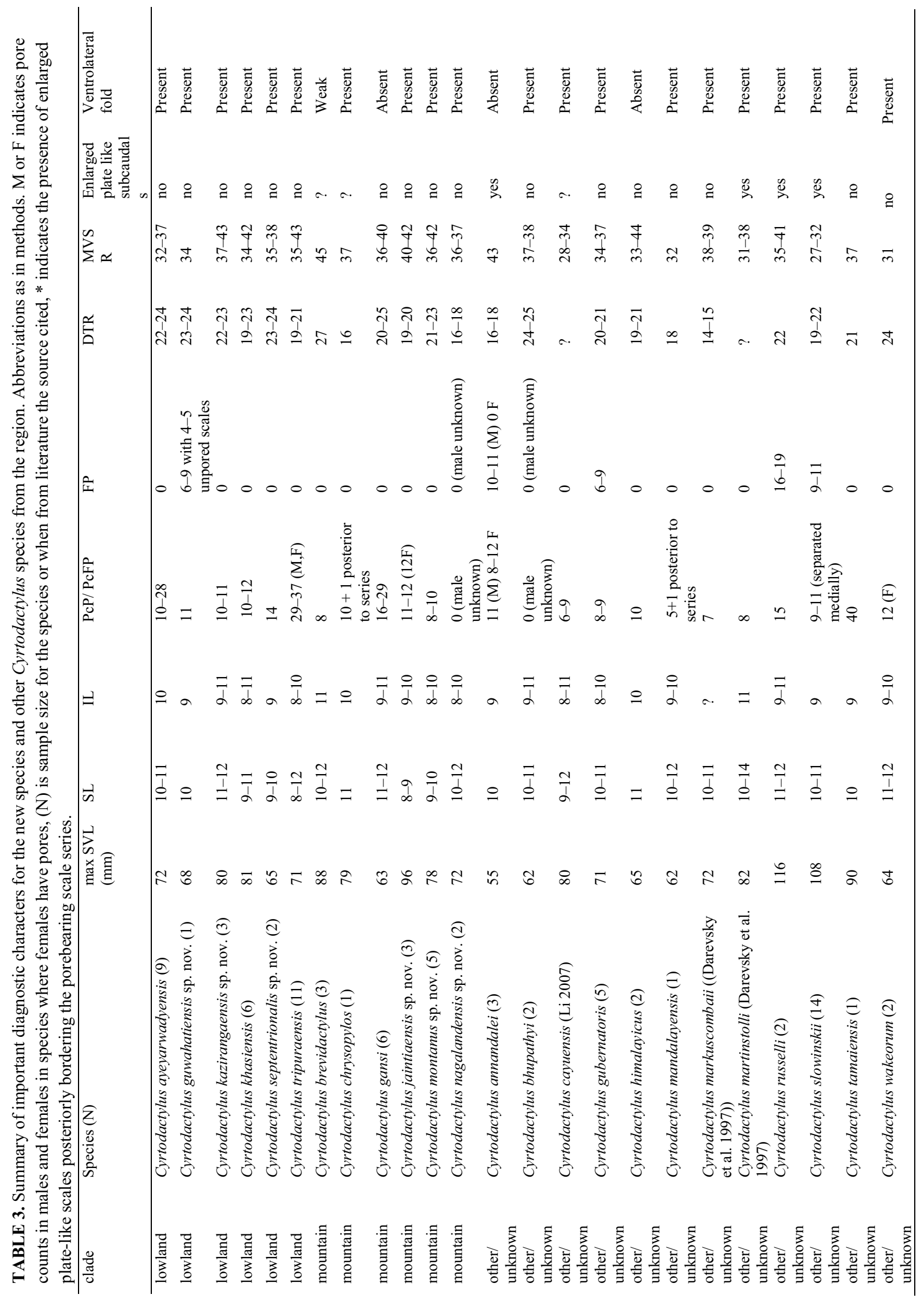




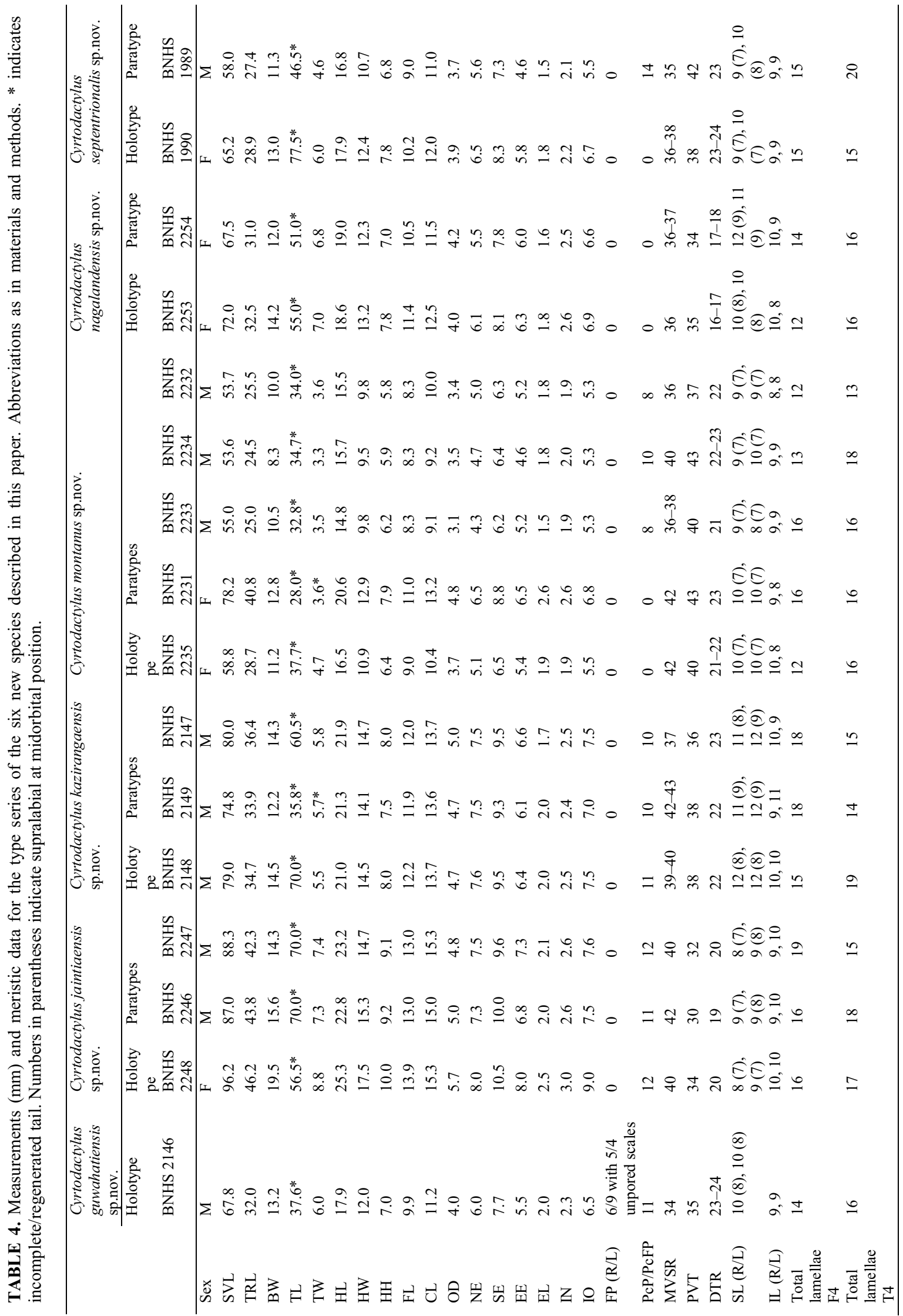




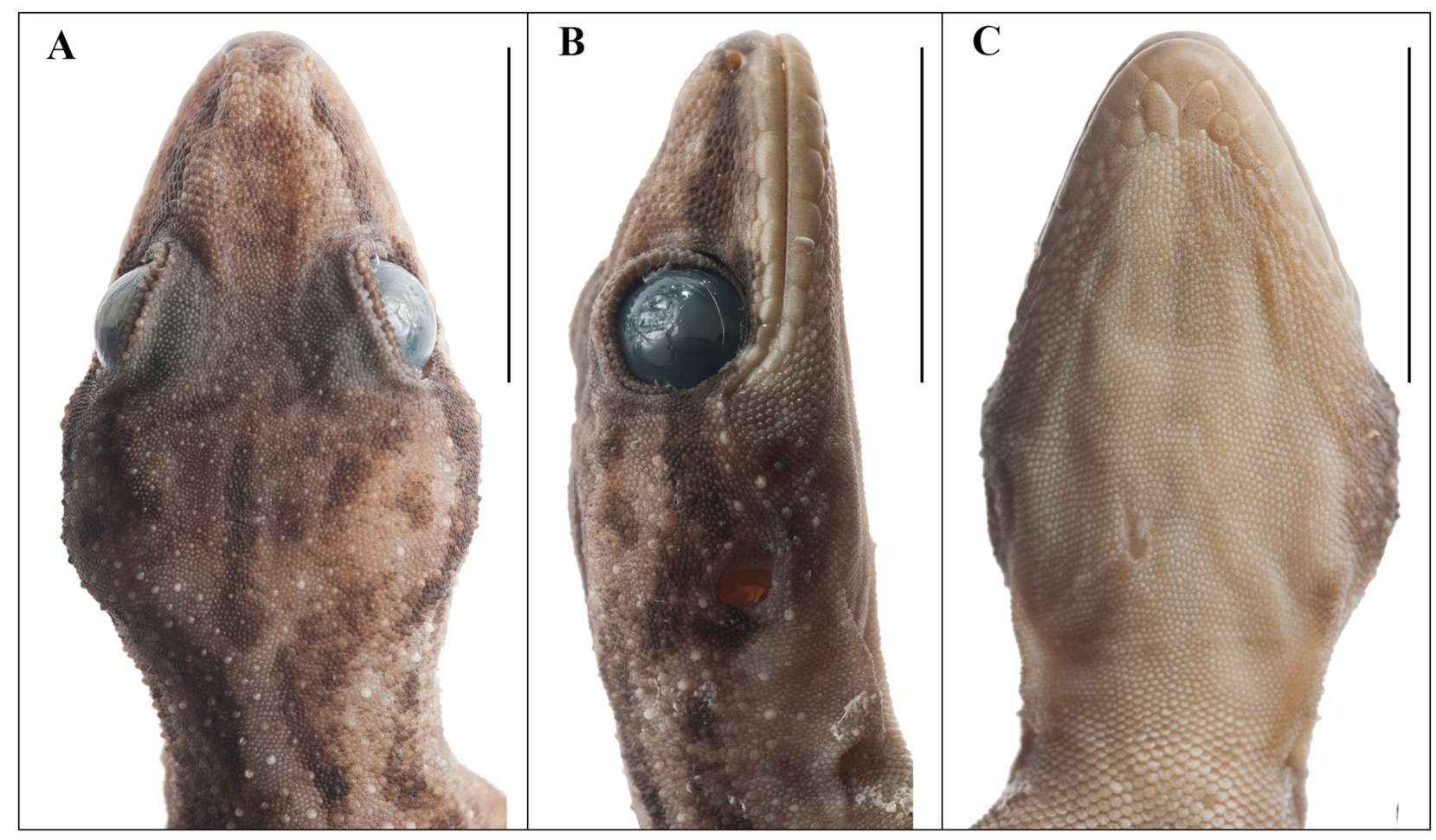

FIGURE 11. Head of Cyrtodactylus septentrionalis sp. nov. (adult female holotype, BNHS 1990), dorsal (A), lateral (B), and ventral (C) view. Scale bars $10 \mathrm{~mm}$.

\section{Cyrtodactylus jaintiaensis sp. nov.}

Figs. 9 and 12-14.

Holotype. Adult female (BNHS 2248, field number CES09/1228), collected from the vicinity of Tyrshi Falls near Jowai town, West Jaintia Hills district, Meghalaya state, India $\left(25.46956^{\circ} \mathrm{N}, 92.18313^{\circ} \mathrm{E}, 1350 \mathrm{~m}\right.$ asl.) by Tarun Khichi, Aniruddha Datta-Roy and Ishan Agarwal on 15 November 2010.

Paratypes. Adult males (BNHS 2246 \& BNHS 2247), bear the same collection data as holotype.

Etymology. The specific epithet is a toponym named after the type locality of the new species in the Jaintia Hills, West Jaintia Hills district, Meghalaya.

Diagnosis. Cyrtodactylus jaintiaensis sp. nov. can be distinguished from all congeners by its large body size (SVL to at least $96.2 \mathrm{~mm}$ ); eight or nine supralabials; nine or 10 infralabials; 19 or 20 longitudinal rows of rounded, conical, feebly keeled dorsal tubercles; tubercles extending to third tail segment; 30-34 paravertebral tubercles; 40-42 ventral scales between ventrolateral folds; no precloacal groove; 11 or 12 precloacal pores on males and females, no femoral pores; a row of enlarged scales posterior to precloacal pore-bearing scales, slightly larger than pore-bearing scales; $15-18$ total subdigital lamellae beneath toe IV of pes; subcaudal scalation of original tail without enlarged subcaudals; dorsal pattern of indistinct light and dark blotches; tail with alternating dark and lighter bands.

Description of holotype. Holotype in good preservation condition: tail tip removed for tissue voucher, constriction just anterior to hind limb insertion due to overzealous tag tying. Adult female, SVL $96.2 \mathrm{~mm}$. Head long (HL/SVL 0.26), slightly wide (HW/HL 0.69), somewhat depressed (HD/HW 0.57), distinct from neck; loreal region somewhat inflated, interorbital region flat, canthus rostralis not prominent; snout short (SE/HL 0.42), twice as long as orbital diameter (ED/SE 0.54); scales on snout and canthus rostralis granular, juxtaposed, homogenous in shape with scales on snout larger; scales on interorbital region, forehead and occipital region smaller, granular, juxtaposed; forehead and occipital region interspersed with larger tubercles that are rounded, smooth and twice the size of adjacent granules, enlarged tubercles sparse on forehead, denser on occipital region. Eye small (ED/HL 0.23 ); pupil vertical with crenulated margins; supraciliaries similar in size and shape to adjacent granules, weakly 
pointed; dorsal surface of eyelids covered with small granular scales, row of enlarged tubercles bordering supraciliaries absent. Ear opening oval, obliquely oriented, large; eye to ear distance larger than diameter of eye (ED/EE 0.71$)$. Rostral wider $(3.6 \mathrm{~mm})$ than deep $(2.0 \mathrm{~mm})$, partially divided dorsally by a weakly developed rostral groove; single much enlarged, rounded supranasals on either side, in contact with each other; rostral in contact with supralabial I, nostrils and supranasals; nostrils oval, laterally oriented, posterior half covered by an indistinct nasal pad, each in broad contact with rostral and surrounded by supranasal, supralabial I, and five smaller, granular postnasal scales; five rows of granular scales between mid-orbit and supralabials; mental wider $(2.8 \mathrm{~mm})$ than deep $(2.2 \mathrm{~mm})$, two well-developed postmentals on either side, inner pair in broad contact $(1.6 \mathrm{~mm})$ with each other behind mental, twice size $(2.3 \mathrm{~mm})$ of and separating outer pair $(1.1 \mathrm{~mm})$; each inner postmental bordered by mental, infralabial I, outer postmental and three gular scales; outer postmentals bordered by inner postmental, infralabials I and II, a large, roughly hexagonal scale posteriorly and three or four slightly enlarged gular scales; seven supralabials on each side at midorbital position; supralabials to angle of jaw, eight on right side and nine on left side, bordered by a row of flat, somewhat elongated scales slightly larger than their adjacent granules; infralabials, 10 on left side, infralabials II-VI bordered by two rows of enlarged scales, anteriormost largest.

Body slender (BW/TRL 0.42), short (TRL/SVL 0.48); dorsal scales heterogeneous, mostly rounded granules, intermixed with irregularly arranged, enlarged tubercles, tubercles rounded, feebly keeled, flatter and more keeled towards vertebral region, more pointed toward flanks; indistinct ventrolateral fold on either side covered by a single row of enlarged smooth scales interspersed with much smaller granules; tubercles extend from occipital region to anterior half of remaining portion of tail; tubercles on nape smaller than those of dorsum; 20 dorsal tubercles across mid-dorsum; 34 paravertebral tubercles; ventral scales much larger than dorsals, smooth, cycloid, subimbricate; slightly smaller under thighs; two rows of enlarged subimbricate scales along posterior border of precloacal pores; 40 ventral scales between ventrolateral folds; gular region with much smaller granular scales throughout, except two rows which are twice as large, flat and juxtaposed, and run from posterior margin of outer postmentals, bordering infralabials; 12 minute precloacal pores in a continuous series; femoral pores absent; no precloacal groove.

Fore and hind limbs slender; forearm (FL/SVL 0.14) and tibia (CL/SVL 0.16) short; digits short, strongly inflected at each joint, all bearing robust recurved claws that are slightly longer than their claw sheath; five subdigital lamellae in basal series and 11 in distal series (digit IV, right manus); seven basal and 10 distal lamellae with three non-lamellar granules at inflection (digit IV, right pes); slight inter-digital webbing between toes I-IV, absent between fingers; relative length of digits: I $<$ II $<$ V $<$ III $<$ IV (right manus) and I $<$ II $<$ V $<$ III $<$ IV (right pes); scales on the palms and soles smooth, flat, juxtaposed, with those on soles being slightly larger; scales on fore limbs heterogeneous, comprising rounded, granular, juxtaposed scales becoming larger, flat, smooth and subimbricate anteriorly; granules of forearms sparsely interspersed with slightly enlarged rounded tubercles; ventral surfaces covered mostly with flat, granular, juxtaposed scales; scales on hind limbs heterogeneous, dorsal part of thighs and shanks with small slightly pointed granular scales, intermixed with scattered, rounded, enlarged, feebly keeled tubercles; ventral aspect of hind limbs with much enlarged, smooth, subimbricate scales.

Tail tip absent, two thirds original, somewhat rounded, slender, tapering, divided into indistinct segments; seven rows of enlarged, rounded, feebly keeled tubercles scattered on tail base; four to six rounded, flattened tubercles at end of first to third segments; remaining dorsal caudal scales smooth, rounded, subimbricate, similar in size dorsally getting larger on lateral aspect; subcaudal scales larger, smooth, imbricate; no distinct median series; three enlarged smooth post cloacal spurs on each side.

Colouration in life (for paratype, BNHS 2246, Fig 12). Dorsal ground colour of head, body, limbs and tail grey-brown, strongly mottled with tan, yellow and white; top of head strongly mottled toward occiput; labials lighter than head dorsum and with some yellow streaks; a light yellow narrow postorbital streak that does not extend as far as ear opening; neck and back with black light grey spots forming a reticulate pattern of thick markings, numerous light and dark brown tubercles on dorsum; limbs with light tan spots; ten dark and nine light caudal bands on complete original tail, dark bands more than four times as wide as light bands; rest of ventral surfaces immaculate; iris green-grey with dark reticulations, pupil bordered by orange-red.

Colouration in preservative (Figs. 13 \& 14). Dorsal ground colour of head, body, limbs and tail light-brown; top of head strongly mottled with fine dark markings; labials similar to top of head bearing scattered darker spots; a light narrow postorbital streak does not extend to ear opening; nape and dorsum bear black and light-grey spots, numerous light and dark brown tubercles on dorsum; limbs with slightly darker reticulate markings; four dark and 
three light bands on original portion of tail, darker bands wider than light, regenerated portion colouration and markings similar to limbs; rest of ventral surfaces dirty white.

Variation. The two adult male paratypes have 11 or 12 distinct precloacal pores and a distinct hemipenal bulge, and are similar in colour pattern to the holotype except there are approximately eight dark and nine light caudal bands on BNHS 2247, and ten dark and nine light caudal bands on BNHS 2246. Variation in scale counts and morphometrics is summarized in Table 4.

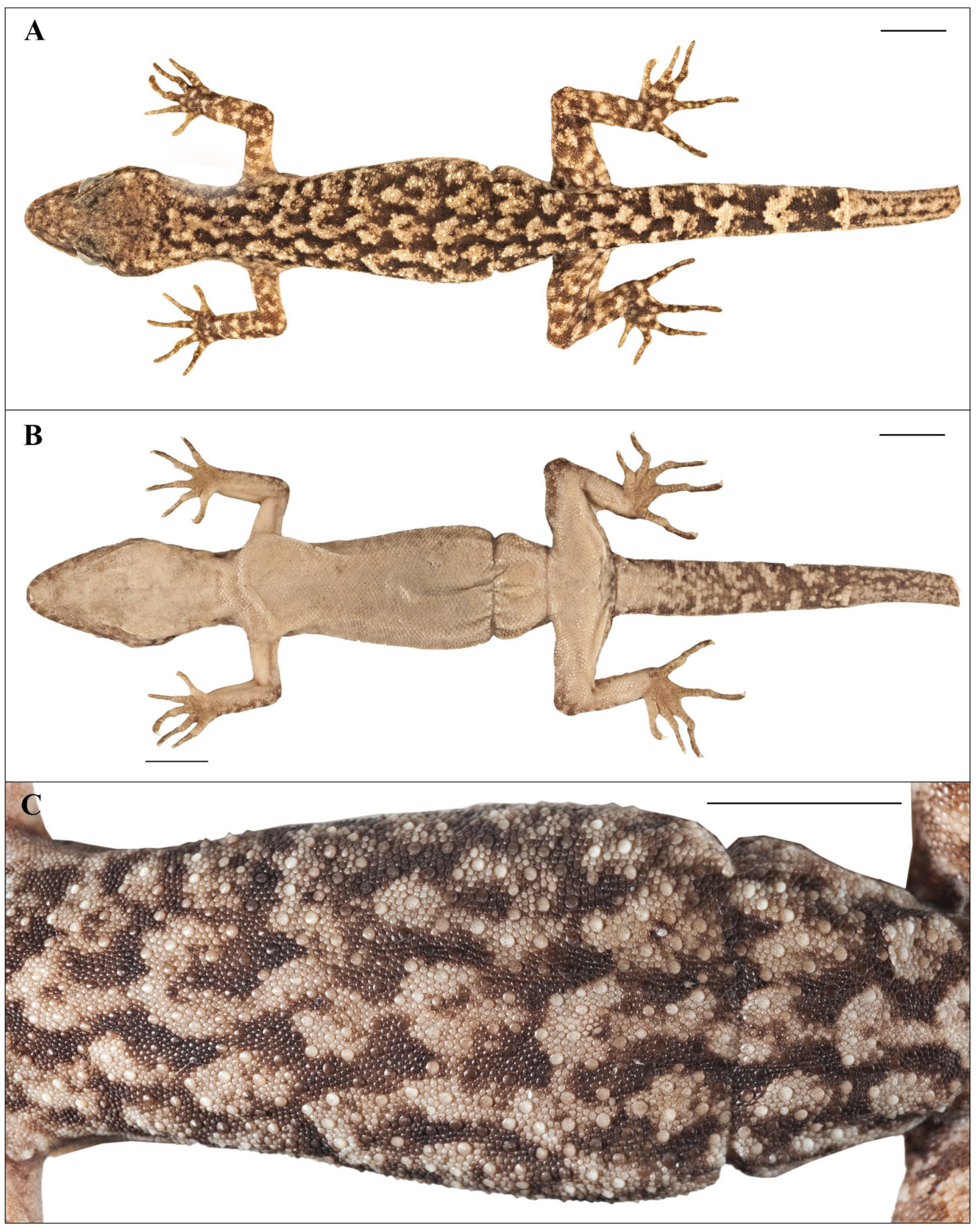

FIGURE 12. Cyrtodactylus jaintiaensis sp. nov. in life (adult male paratype, BNHS 2246). 


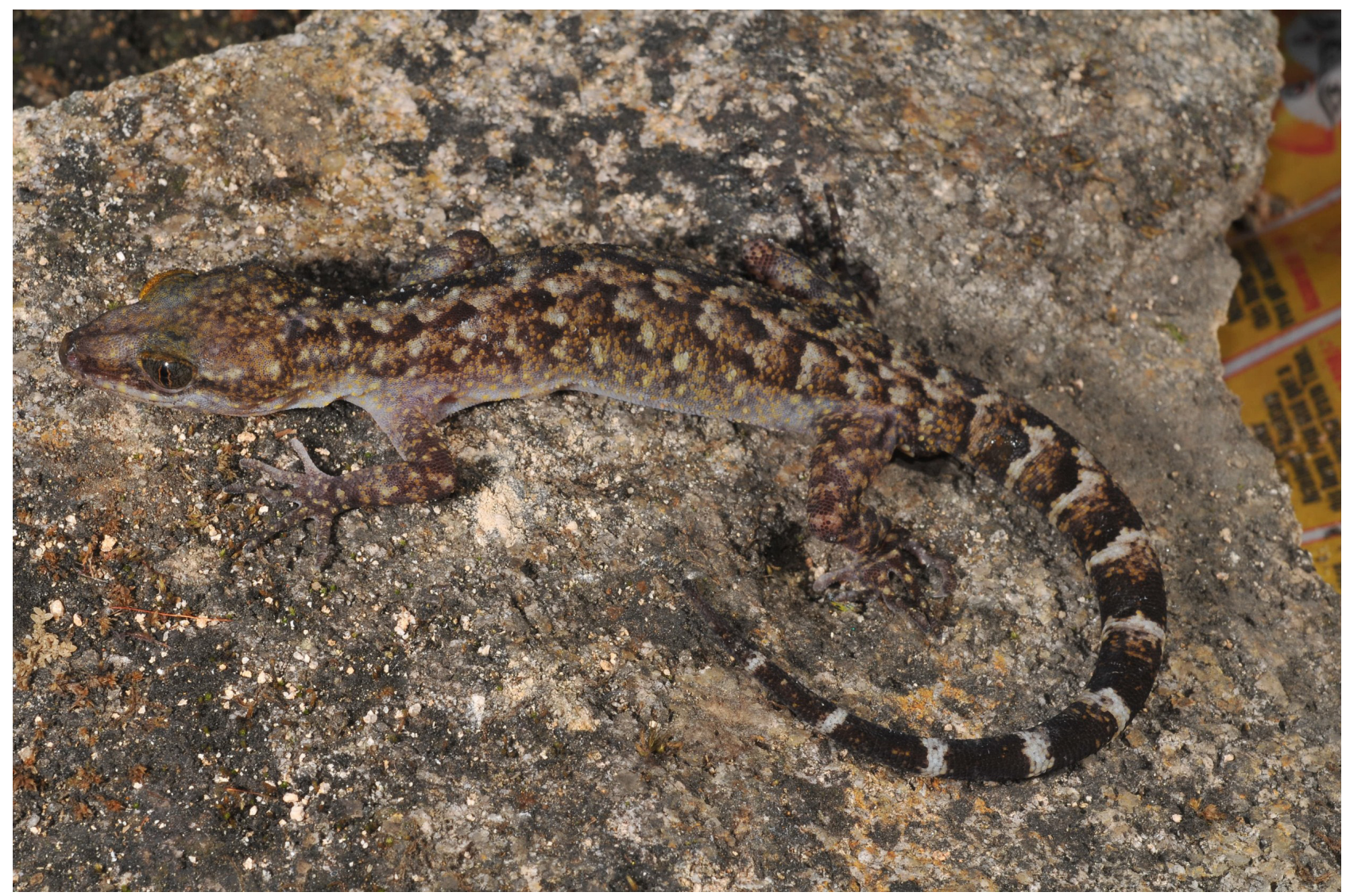

FIGURE 13. Dorsal view (A), ventral view (B), and details of dorsal pholidosis (C) of adult female holotype (BNHS 2248) of Cyrtodactylus jaintiaensis sp. nov. Scale bars $10 \mathrm{~mm}$.

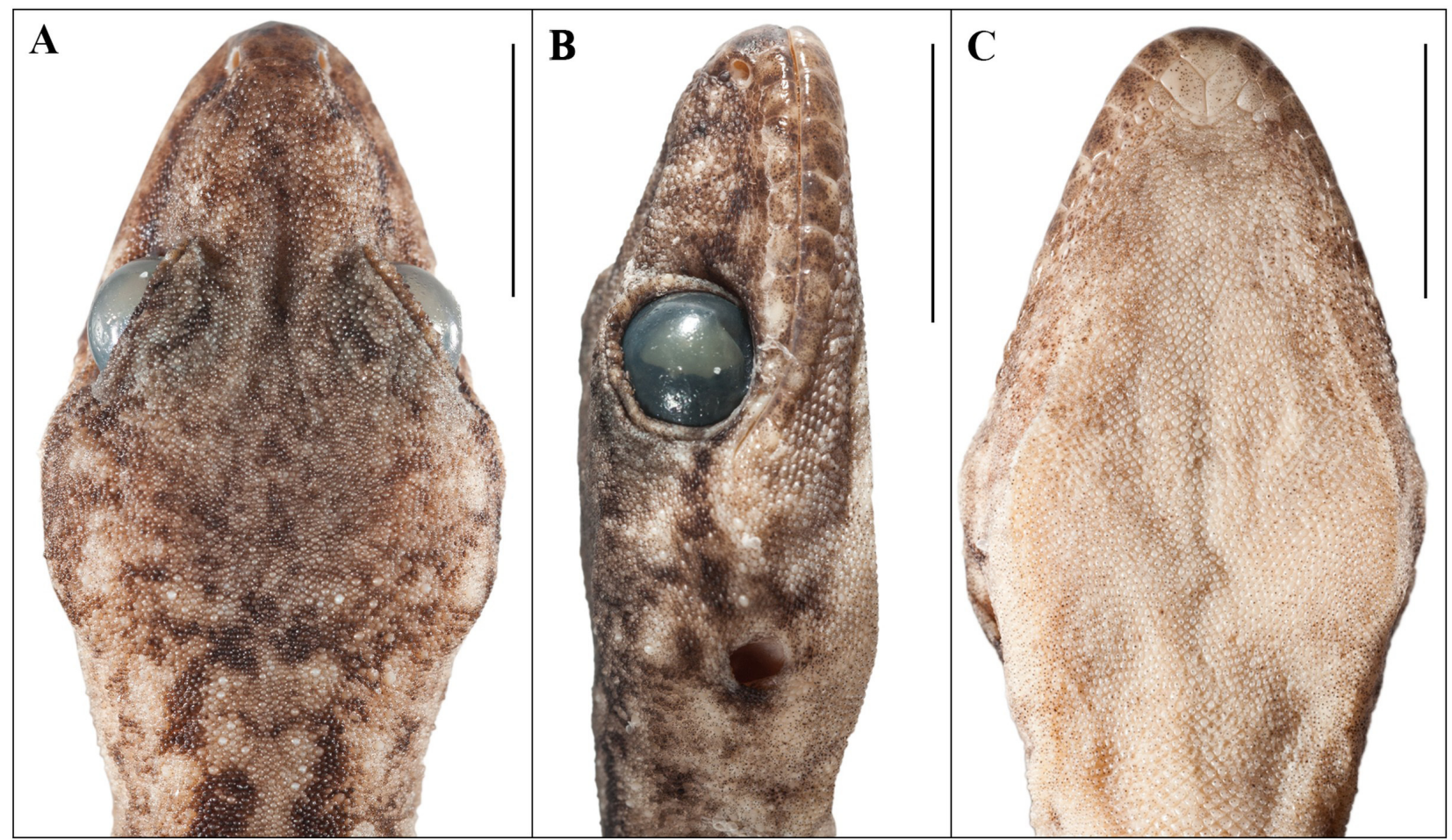

FIGURE 14. Head of Cyrtodactylus jaintiaensis sp. nov. (adult female holotype, BNHS 2248), dorsal (A), lateral (B), and ventral (C) view. Scale bars $10 \mathrm{~mm}$. 
Distribution and Natural History. The species is only known from the vicinity of Tyrshi Falls, in the Jaintia Hills. The geckos were spotted at night by eye-shine on vertical rock faces. The landscape is made up of patches of forest in an agricultural matrix.

Comparisons. Cyrtodactylus jaintiaensis sp. nov. is a member of the mountain clade and is the poorly supported sister lineage to $C$. montanus sp. nov. and $C$. sp. Mizoram, and is separated from members of the clade by pairwise uncorrected genetic distance of approximately $18.7-21.4 \%$. Cyrtodactylus jaintiaensis sp. nov. can be diagnosed by its large body size (SVL up to $96 \mathrm{~mm}$ ), and the presence of 11 or 12 precloacal pores in a single series in males from $C$. chrysopylos (SVL up to $79 \mathrm{~mm}$, enlarged pore-bearing post-precloacal scales in males), and $C$. gansi (SVL up to $63 \mathrm{~mm}, 16-29 \mathrm{PcFP}$ ). Cyrtodactylus jaintiaensis sp. nov. can be diagnosed by its reticulate dorsal pattern from C. brevidactylus (3-dark dorsal blotches between nape and sacrum). The differentiation of $C$. jaintiaensis sp. nov. from $C$. montanus sp. nov., and $C$. nagalandensis sp. nov. is detailed following their descriptions. Major diagnostic characters for the new species and regional congeners are summarized in Table 3.

\section{Cyrtodactylus montanus sp. nov.}

Figs. 9 and $15-17$

Holotype. Adult female (BNHS 2235, field number CES09/1215), collected from near Phuldungsei village in the southern Jampui Hills, Kanchanpur subdivision, North Tripura district, Tripura state, India $\left(23.82257^{\circ} \mathrm{N}\right.$, $92.26034^{\circ} \mathrm{E}, 850 \mathrm{~m}$ asl.) by Tarun Khichi, N.P.I. Das, Aniruddha Datta-Roy and Ishan Agarwal on 3 November 2010.

Paratypes. Adult males (BNHS 2232-2234) and an adult female (BNHS 2231), bear the same collection data as the holotype.

Etymology. The specific epithet is a nominative, masculine, singular, Latin adjective meaning "pertaining to a mountain" as this species is a member of the mountain clade, and is restricted to a mountainous region in northwestern Tripura.

Diagnosis. Cyrtodactylus montanus sp. nov. can be distinguished from all congeners by its moderate body size (SVL to at least $78.2 \mathrm{~mm}$ ); eight or 10 supralabials; 8-10 infralabials; 21-23 longitudinal rows of rounded, conical, feebly keeled dorsal tubercles; tubercles extending posteriorly to at least third tail segment; 37-43 paravertebral tubercles; 21-23 ventral scales between ventrolateral folds; no precloacal groove; 8-10 precloacal pores in males, no femoral pores; a row of enlarged scales posterior to precloacal pore-bearing scales, slightly larger than porebearing scales; 13-18 total subdigital lamellae beneath toe IV of pes; subcaudal scalation lacking enlarged median plates; dorsal colour pattern of thick dark reticulations enclosing lighter blotches; tail with alternating dark and lighter bands.

Description of holotype. Holotype in good preservation condition: tail tip removed for tissue voucher, toe V of pes missing, constriction just above hind limb insertion due to overzealous tag tying, small abrasion on gular region, and folds of skin on dorsal surface of head, all artefacts of preservation and storage. Adult female, SVL $58.8 \mathrm{~mm}$. Head long (HL/SVL 0.28), slightly wide (HW/HL 0.66), dorsoventrally depressed (HD/HW 0.58), distinct from neck; loreal region inflated, interorbital region flat, canthus rostralis not prominent; snout short (SE/ HL 0.39), twice as long as orbital diameter (ED/SE 0.57); scales on snout and canthus rostralis, granular, juxtaposed, homogenous in shape with scales on snout being slightly larger; scales on interorbital region, forehead and occipital region slightly smaller, granular, juxtaposed; forehead and occipital region interspersed with larger tubercles that are rounded, smooth and two to four times size of adjacent granules; dense enlarged tubercles slightly smaller on forehead and larger on occipital region. Eye small (ED/HL 0.22); pupil broad, vertical with crenulated margins; supraciliaries only slightly larger than adjacent scales, weakly pointed; upper eyelids covered with small granular scales, row of enlarged tubercles bordering supraciliaries absent. Ear opening oval, obliquely oriented, large; eye to ear distance less than twice diameter of eye (ED/EE 0.69). Rostral wider (2.3 mm) than deep (1.1 $\mathrm{mm}$ ), partially divided dorsally by a weakly developed rostral groove; single enlarged rounded supranasal on either side, separated from each other by two rows of two smaller granular internasal scales; rostral in contact with supralabials I, nostrils, supranasals and two small internasals separating supranasals; nostrils oval, laterally oriented, posterior half covered by a distinct nasal pad, each in broad contact with rostral and surrounded by supranasal, supralabial I, and five small granular postnasal scales; five rows of granular scales between mid-orbit 
and supralabials; mental wider $(1.8 \mathrm{~mm})$ than deep $(1.2 \mathrm{~mm})$, triangular, two well-developed postmentals on either side, inner pair in broad contact $(1.4 \mathrm{~mm})$ behind mental, twice as large $(1.8 \mathrm{~mm})$ and separating outer pair from each other (0.9); each inner postmental bordered by mental, infralabial I, outer postmental and a row of two or three gular scales; outer postmentals bordered by inner postmental, infralabial I and II, a large, roughly hexagonal scale posteriorly and three gular scales that are twice size of other gular scales; seven supralabials at midorbital positionand 10 to angle of jaw, bordered by a row of flat, somewhat elongated scales slightly larger than their adjacent granules; eight infralabials on left side, ten on right side, infralabials I-V bordered by one or two rows of enlarged scales, anteriormost largest.

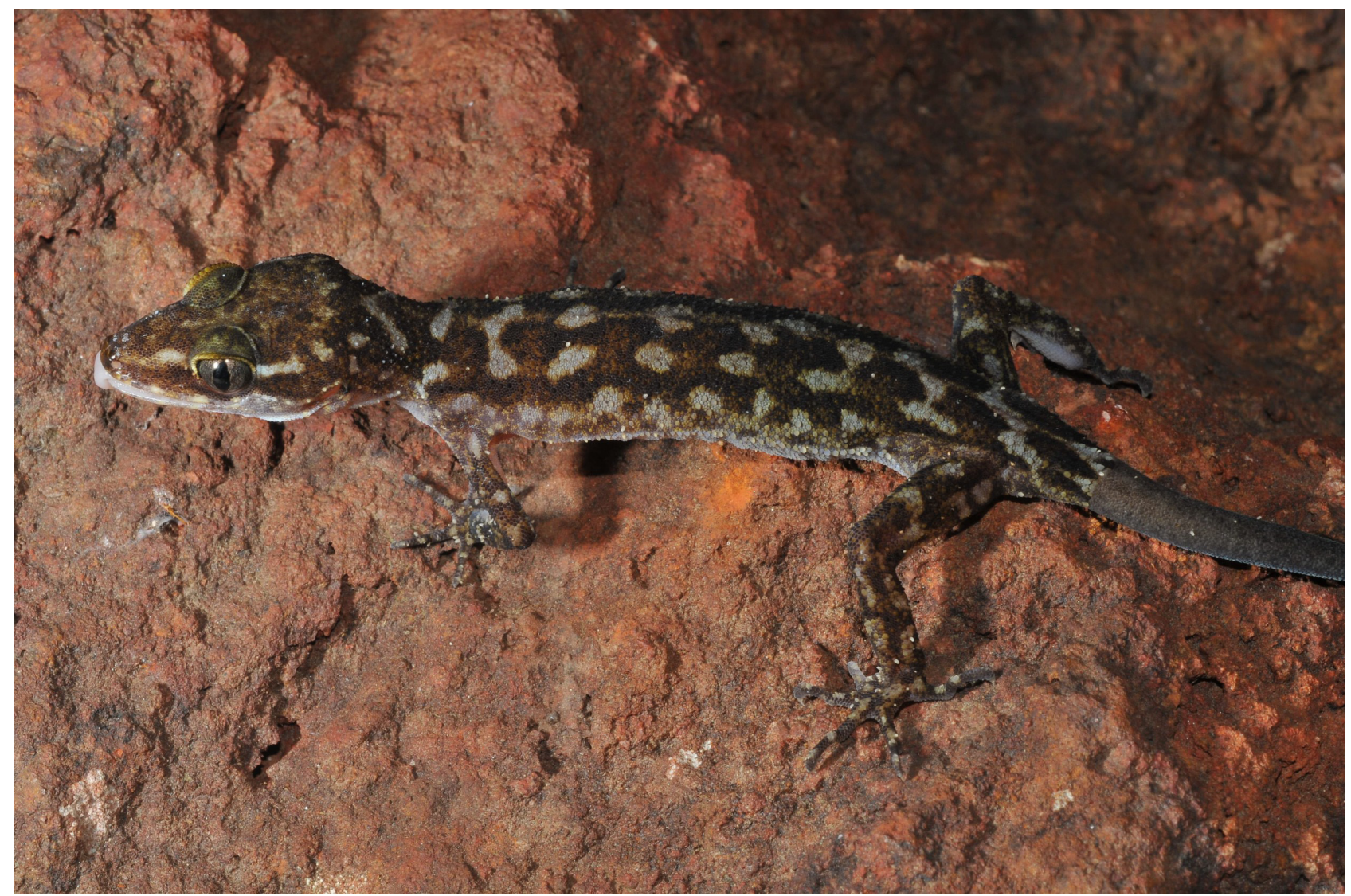

FIGURE 15. Cyrtodactylus montanus sp. nov. in life, adult females; top panel paratype BNHS 2231; lower panel uncollected female from the type locality.

Body slender (BW/TRL 0.39), short (TRL/SVL 0.49); dorsal scales heterogeneous, mostly rounded granules intermixed with enlarged tubercles that are irregularly arranged, rounded, feebly keeled to slightly conical, and more or less homogenous in shape and size throughout dorsum; an indistinct ventrolateral fold on either side comprises a single row of small conical tubercles; tubercles extend anteriorly onto eyelids and frontal region; tubercles on nape smaller than those of dorsum; 21 or 22 dorsal tubercles across mid-dorsum; 40 paravertebral tubercles; ventral scales much larger than dorsals, smooth, cycloid, subimbricate; slightly smaller in size under thighs; a row of enlarged subimbricate scales along posterior border of precloacal scales; 42 ventral scales between ventrolateral folds; gular region with much smaller granular scales throughout, except two rows bordering infralabials originating from posterior margin of outer postmentals, which are larger, flat and juxtaposed. A continuous series of eight enlarged precloacal scales, each with a shallow depression, no precloacal or femoral pores, no precloacal groove.

Fore and hind limbs slender; forearm (FL/SVL 0.15) and tibia (CL/SVL 0.18) short; digits short, strongly inflected at each joint, all bearing robust recurved claws that are only slightly longer than their respective claw sheaths; four subdigital lamellae in basal series and eight in distal series with one non-lamellar granule at inflection (digit IV, right manus); six basal and 10 distal lamellae with one non-lamellar granule at inflection (digit IV, right pes); inter-digital webbing absent; relative length of digits: I $<$ II $<$ V $<$ III $<$ IV (left manus) and I $<$ II $<$ V $<$ III $<$ IV (left pes); scales on the palms and soles smooth, flat, juxtaposed; scales on fore limbs heterogeneous, composed 
of rounded, granular, juxtaposed scales, becoming flat, smooth and subimbricate anteriorly; granules of upper arms and forearms densely interspersed with slightly enlarged rounded tubercles; ventral portion covered mostly with flat, granular, juxtaposed scales; scales on hind limbs heterogeneous, dorsal part of thighs and shanks with small slightly pointed granular scales, intermixed with scattered, enlarged, weakly pointed tubercles; ventral aspect of hind limbs with enlarged, smooth, subimbricate scales.

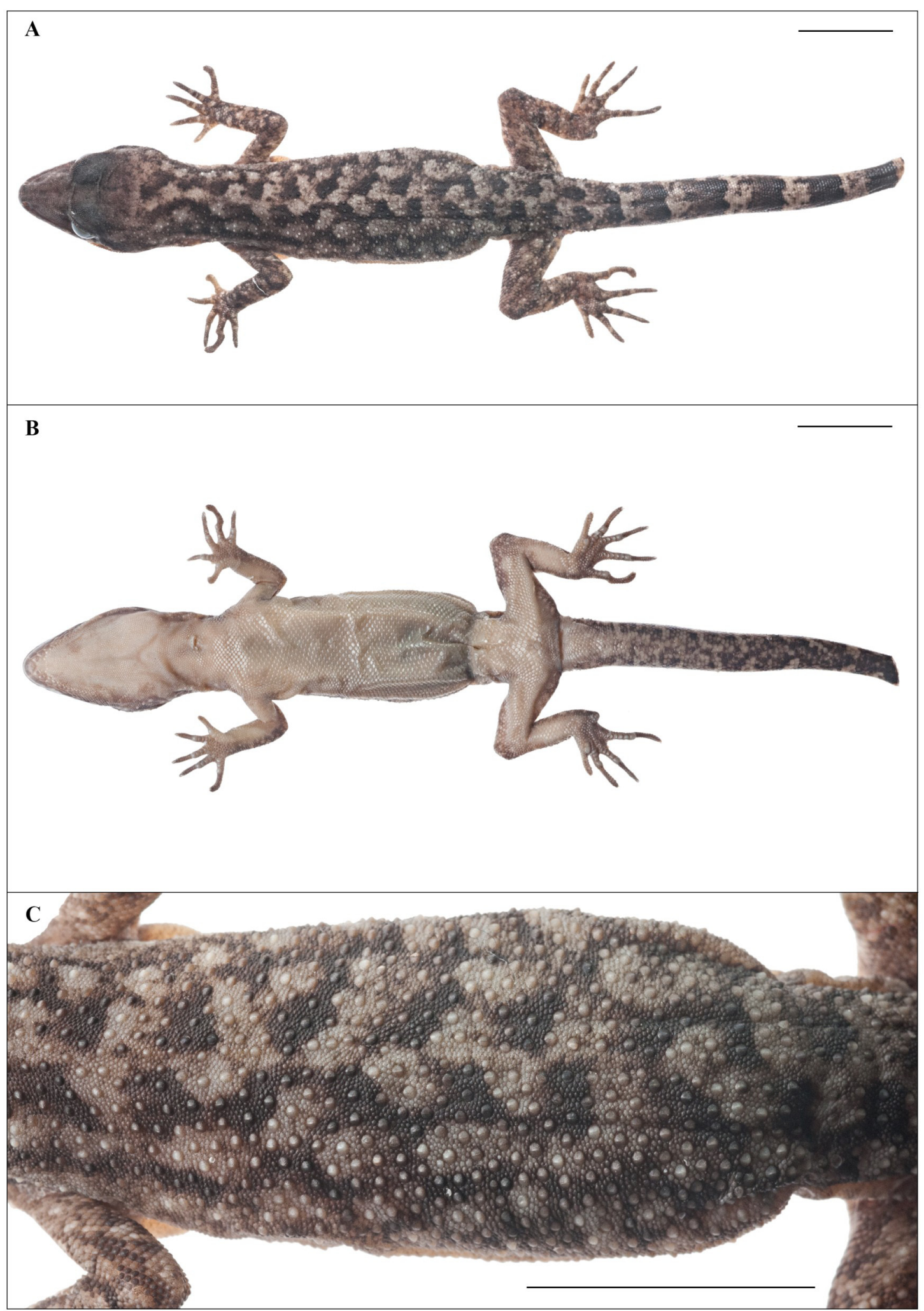

FIGURE 16. Dorsal view (A), ventral view (B), and details of dorsal pholidosis (C) of adult female holotype (BNHS 2235) of Cyrtodactylus montanus sp. nov. Scale bars $10 \mathrm{~mm}$. 
Tail original with tip removed, somewhat rounded, slender, tapering, divided into indistinct segments; about ten rows of enlarged keeled sub-trihedral tubercles scattered on tail base; $2-5$ conical tubercles at end of first to third segments; remaining dorsal caudal scales smooth, rounded, subimbricate, similar in size dorsally and on lateral aspect; subcaudal scales larger than dorsal, smooth, imbricate; no distinct mid-ventral series of enlarged subcaudals; three enlarged smooth post cloacal spurs on each side.

Colouration in life. Not documented for holotype.

Colouration in preservative (Figs. 16 \& 17). Dorsal ground colour of head, body, limbs and tail brown; top of head with indistinct darker markings; labials darker than head dorsum with about one light brown blotch per labial; a discontinuous light postorbital streak extends to above ear opening; neck with two longitudinal discontinuous dark streaks; dorsum and dorsolateral aspect with about eight rows of four dark paravertebral blotches; limbs with light grey and tan spots; seven dark and light caudal bands, dark bands twice as wide as light bands; rest of ventral surfaces off-white, immaculate.

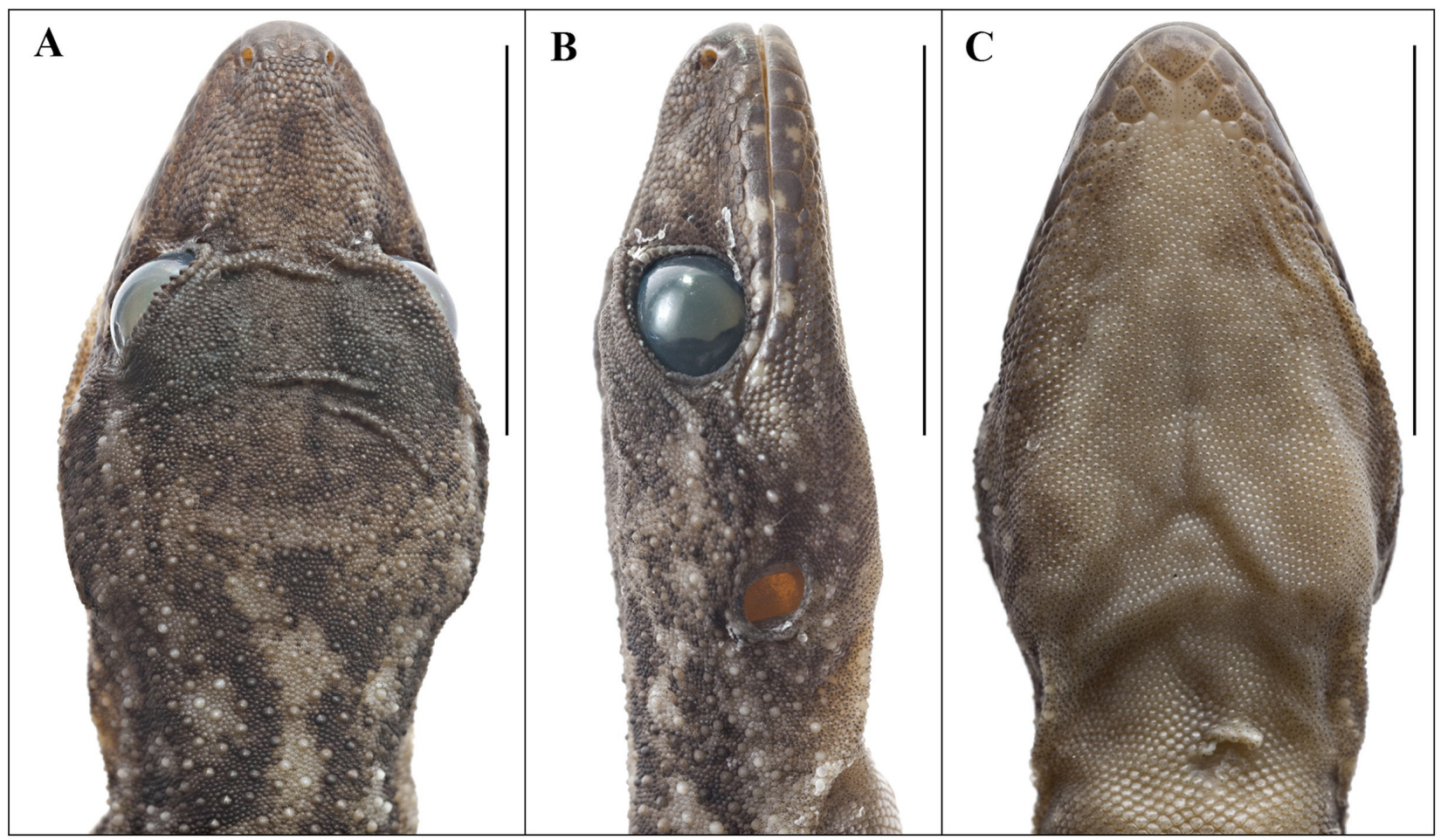

FIGURE 17. Head of Cyrtodactylus montanus sp. nov. (adult female holotype, BNHS 2235), dorsal (A), lateral (B), and ventral $(C)$ view. Scale bars $10 \mathrm{~mm}$.

Variation (Fig 9). Compared to the holotype, BNHS 2231 has much thicker dark dorsal markings, regenerated tail without spots, an inverted light chevron shaped marking on occiput flanked on either side by a similar coloured spot; postorbital streaks interrupted but meet on base of head; dark and light bands on tail of approximately equal width in some types. The male paratypes have a continuous series of 8-10 precloacal pores (Table 4), except BNHS 2233 which has four pores on each side separated by a median unpored scale.

Distribution and Natural History. Cyrtodactylus montanus sp. nov. is known only from its type locality, in the Jampui Hills. We collected the type series from rocky roadside cuttings on a mountain-top in approximately one-half of an hour of searching after dark. This high elevation region has a small patch of montane evergreen forest, as opposed to deciduous forest at lower elevations where C. tripuraensis is distributed. A couple of additional populations were observed but not collected in other parts of the Jampui Hills. These populations are provisionally referred to this species due to overall morphological similarity with the type series. One female was found near the peak $\left(\sim 23.8098^{\circ} \mathrm{N}, 92.2610^{\circ} \mathrm{E}, \sim 920 \mathrm{~m}\right.$ asl.) of Betalongchhip (or Thaidawr: highest peak in Tripura state) approximately $1 \mathrm{~km}$ south of Phuldungsei. The individual was located during dusk emerging from a tree hole at approximately $1.5 \mathrm{~m}$ above ground level within a forest patch. Two additional populations photographed but not collected were observed $\sim 20 \mathrm{~km}$ north of the type locality near Vanghmun $\left(\sim 24.0055^{\circ} \mathrm{N}, 92.2817^{\circ} \mathrm{E}, \sim 600 \mathrm{~m}\right.$ asl. $)$. 
Eight adult individuals (three males and five females) were observed on an old brick wall after dusk on consecutive nights during the months of June to mid August, after which this population appeared to have dispersed from the wall, as none were observed on the wall during several visits in late August. Nearby the old brick wall was a large dense bamboo brake. Adults spent the day concealed within holes in the wall, emerging only after dusk where they were observed in the open, typically spaced $>1.5 \mathrm{~m}$ apart. This population had considerable variation in dorsal markings. Elsewhere near Vanghmun, a male and female were observed on a steep rocky roadside embankment about $1 \mathrm{~h}$ after night-fall. Three females observed during late August were gravid with a large pair of eggs (visible through the skin).

Comparisons. Cyrtodactylus montanus sp. nov. is a member of the mountain clade and is sister to $C$. sp. Mizoram from which it differs by $10.1 \%$ uncorrected ND2 $p$-distance, separated from other members of the clade by $p$-distance of 19.0-21.5\%. Cyrtodactylus montanus sp. nov. can be diagnosed by the presence of 8-10 precloacal pores in a single series (or separated medially by a single scale) in males only from C. gansi (16-29 PcFP) and Cyrtodactylus jaintiaensis sp. nov. (11-12 PcP on both males and females), also distinguished from the latter by its slightly smaller size (SVL up to $78.2 \mathrm{~mm}$ vs. up to $96.2 \mathrm{~mm}$ ); and by the number of dorsal tubercle rows (21-23) from C. brevidactylus (27 DTR) and C. chrysopylos (16 DTR). Cyrtodactylus montanus sp. nov. is distinguished from Cyrtodactylus nagalandensis sp. nov. after its description. Major diagnostic characters for the new species and regional congeners are summarized in Table 3.

\section{Cyrtodactylus nagalandensis sp. nov.}

Figs. 9 and $18-20$.

Holotype. Adult female (BNHS 2253, field number CES09/1233) collected from near Khonoma village, Kohima district, Nagaland state, India $\left(25.65818^{\circ} \mathrm{N}, 94.02142^{\circ} \mathrm{E}, 1450 \mathrm{~m}\right.$ asl.) by Ishan Agarwal on 23 October 2009.

Paratype. Adult female (BNHS 2254) bears the same collection information as holotype.

Etymology. This is the first endemic gecko from Nagaland, and the specific epithet is a toponym for the state.

Diagnosis. Cyrtodactylus nagalandensis sp. nov. can be distinguished from all congeners by its moderate body size (SVL to at least $72.0 \mathrm{~mm}$ ); 10-12 supralabials; 8-10 infralabials; 16-18 longitudinal rows of rounded, conical, feebly keeled dorsal tubercles; tubercles extending posteriorly to third tail segment; 35-37 paravertebral tubercles; 34 or 35 ventral scales between ventrolateral folds; no precloacal groove; six depressions in precloacal series but no precloacal or femoral pores on females, male condition unknown; 16 total subdigital lamellae beneath toe IV of pes; subcaudal scalation of original tail with paired enlarged subcaudals not forming median plates; dorsal pattern of indistinct light and dark blotches forming longitudinal markings on neck and forebody; tail with alternating dark and lighter bands.

Description of holotype. Holotype in good preservation condition: tail tip removed for tissue voucher, tail curved towards left, with folds of skin along either side of ventrolateral aspect; constriction around midbody due to overzealous tag tying, toes on left and right pes recurved; all artifacts of preservation. Adult female, SVL $72.0 \mathrm{~mm}$. Head long (HL/SVL 0.30), slightly wide (HW/HL 0.70), dorsoventrally depressed (HD/HW 0.59), distinct from neck; loreal region inflated, interorbital region flat, canthus rostralis not prominent; snout short (SE/HL 0.40), twice as long as orbital diameter (ED/SE 0.50); scales on snout and canthus rostralis granular, juxtaposed, homogenous in shape, with scales on snout being slightly larger; scales on interorbital region, forehead and occipital region slightly smaller, granular, juxtaposed; forehead and occipital region interspersed with larger tubercles that are rounded, smooth and two to four times the size of adjacent granules; enlarged tubercles smallest on anterior and central parietal regions, increasing in size laterally and posteriorly. Eye small (ED/HL 0.20); pupil vertical with crenulated margins; supraciliaries roughly triangular, pointed, decreasing in size towards posterior and anterior ends of orbit, largest about one-third the way from anterior edge of orbit; dorsal surface of eyelid primarily covered with small granular scales except a single row of granular scales bordering anterior supraciliaries are enlarged relative to adjacent granular scales. Ear opening oval, obliquely oriented; eye to ear distance almost twice diameter of eye (ED/EE 0.60$)$. Rostral wider $(2.7 \mathrm{~mm})$ than deep $(1.8 \mathrm{~mm})$, partially divided dorsally by a weakly developed rostral groove; single enlarged rounded supranasals on either side, separated by a smaller, roughly hexagonal internasal scale which is about three times size of granules on snout; rostral in contact with supralabials I, nostrils, supranasals and a single internasal; nostrils oval, laterally oriented, posterior half covered 
by a conspicuous nasal pad, each in broad contact with rostral and surrounded by supranasal, supralabial I, and four smaller granular postnasal scales; one to three rows of granular scales separate orbit from supralabials; mental wider $(3.1 \mathrm{~mm})$ than long $(1.8 \mathrm{~mm})$, triangular, two pairs of well-developed postmentals on either side, inner pair in broad contact $(0.9 \mathrm{~mm})$ with each other posteriorly behind mental, inner pair larger $(1.8 \mathrm{~mm})$ than and separating outer pair (1.2); each inner postmental bordered by mental, infralabial I, outer postmental and a row of four or five gular scales of similar size to other gulars; outer postmentals each bordered by inner postmental, infralabials I and II, a large, roughly hexagonal scale posteriorly and four or five gular scales; eight supralabials to midorbital position and 10 to angle of jaw on each side, bordered by a row of flat, somewhat elongated scales slightly larger than their adjacent granules; infralabials, 10 on right side and eight on left side, infralabials II to V bordered by a row of enlarged scales, anteriormost largest.

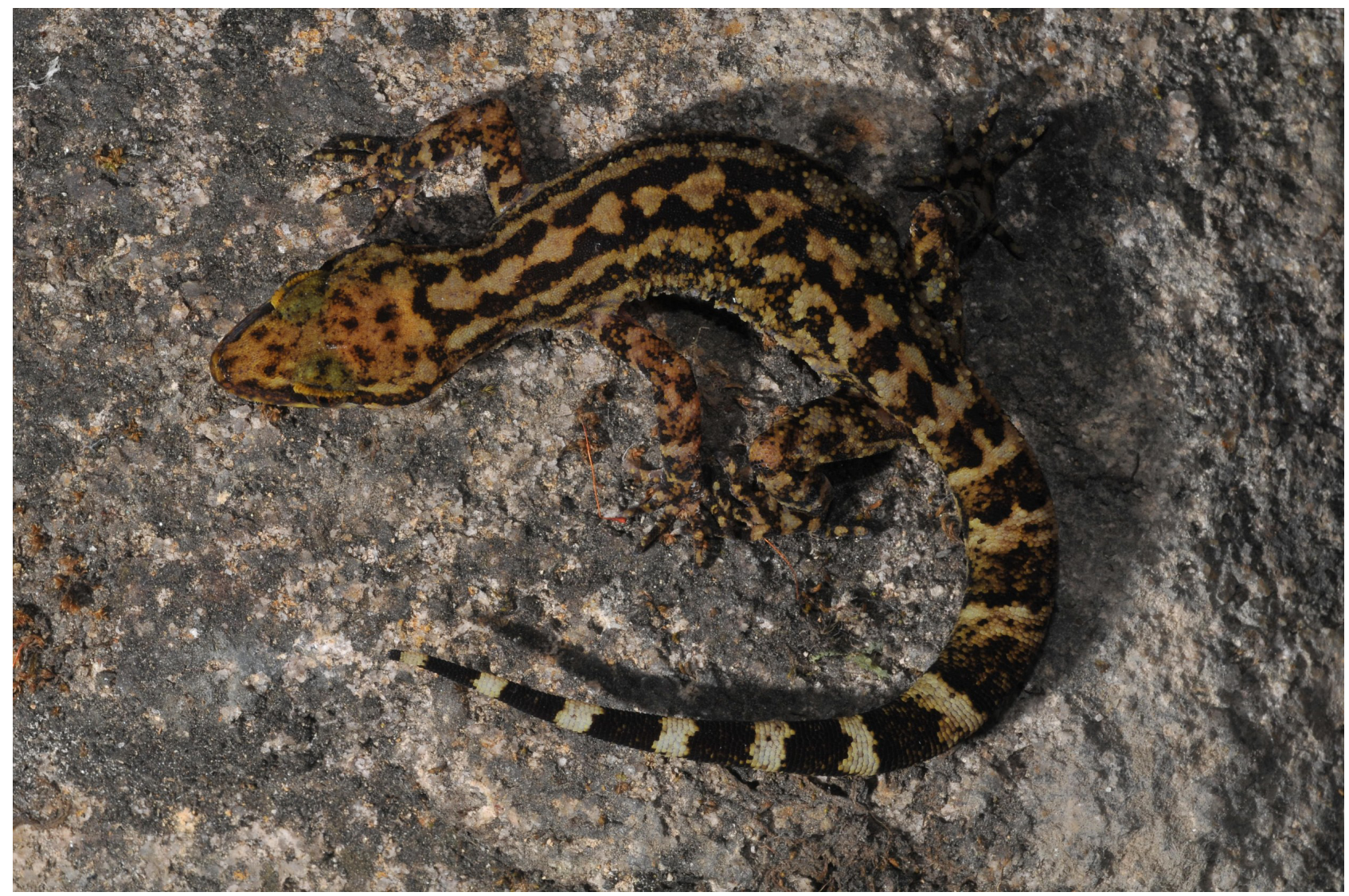

FIGURE 18. Cyrtodactylus nagalandensis sp. nov. in life (adult female holotype, BNHS 2253).

Body slender (BW/TRL 0.4), short (TRL/SVL 0.50); dorsal scales heterogeneous with mostly rounded granules, intermixed with irregularly arranged enlarged tubercles, rounded, conical, feebly keeled, decreasing in size towards vertebral region; tubercles extend anteriorly to interorbital region; tubercles on nape smaller than those of dorsum; dorsal tubercles in 16 or 17 longitudinal rows at mid-dorsum; 35 paravertebral tubercles; a distinct ventrolateral fold on either side covered by a series of slightly enlarged, flat, granular scales; ventral scales much larger than dorsals, smooth, cycloid, subimbricate; a row of enlarged subimbricate scales along posterior border of precloacal pores; 36 ventral scales between ventrolateral folds; gular region with much smaller, granular scales throughout except for one or two rows originating from posterior margin of outer postmentals bordering infralabials, which are larger, flat and juxtaposed. A continuous series of six enlarged precloacal scales each with a shallow depression, precloacal and femoral pores absent, no precloacal groove.

Fore and hind limbs slender; forearm (FL/SVL 0.20) and tibia (CL/SVL 0.20) short; digits short, strongly inflected at each joint, all bearing robust recurved claws that are slightly longer than their associated claw sheath; five subdigital lamellae in basal series and seven in distal series with four non-lamellar granules at inflection (digit IV, right manus); five basal and 11 distal lamellae with one non-lamellar granule at inflection (digit IV, right pes); slight inter-digital webbing between toes I-III, absent between fingers; relative length of digits: I $<$ II $<$ V $<$ III $<$ IV (right manus) and I $<$ II $<$ V $<$ III $<$ IV (right pes); scales on palms and soles smooth, flat, juxtaposed, with those 
on soles being slightly larger; scales on fore limbs heterogeneous, composed of large, rounded, granular, juxtaposed scales becoming flatter, smooth and subimbricate anteriorly; granules of upper arms larger than those on forearms, sparsely interspersed with slightly enlarged rounded tubercles; ventral portion of fore limbs covered mostly with flat, granular, juxtaposed scales; scales on hind limbs heterogeneous, dorsal part of thighs and shanks with small, rounded, granular scales, scattered densely with rounded, enlarged, feebly keeled tubercles; ventral aspect of hind limbs with enlarged, smooth, subimbricate scales.

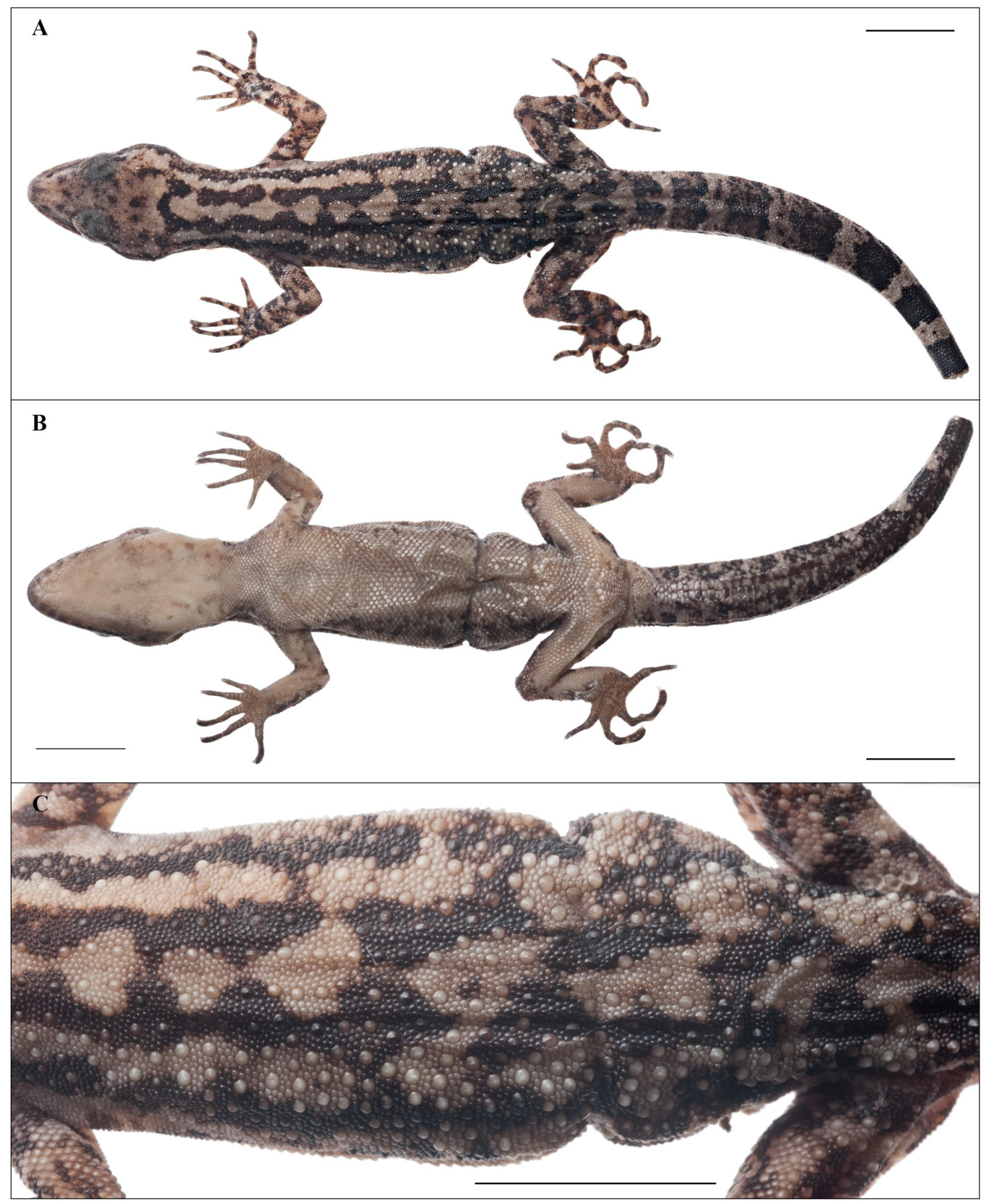

FIGURE 19. Dorsal view (A), ventral view (B), and details of dorsal pholidosis (C) of adult female holotype (BNHS 2253) of Cyrtodactylus nagalandensis sp. nov. Scale bars $10 \mathrm{~mm}$. 
Tail original with tip removed, somewhat rounded, slender, tapering, divided into indistinct segments; eight rows of enlarged, sub-trihedral, strongly keeled tubercles on tail base; approximately four rounded, flattened tubercles form a transverse row at posterior border of each of first three segments; remaining dorsal caudal scales smooth, rounded, subimbricate, similar in size dorsally getting slightly larger on lateral aspect; subcaudal scales larger, smooth, imbricate; a distinct mid-ventral series comprising of two large scales; enlarged smooth post cloacal spurs, three on left side and two on right side.

Colouration in life (Fig. 18). Dorsal ground colour of head, body, limbs and tail buff-brown; top of head with numerous dark spots; labials strongly suffused with yellow; a dark postorbital streak that extends beyond ear opening; neck and back with black spots that form longitudinal markings on neck and forebody; limbs with indistinct darker bars and spots; 11 dark and 10 light caudal bands, dark bands more than twice as wide as light bands; rest of ventral surfaces immaculate; iris green-grey with dark reticulations, pupil bordered by orange-red

Colouration in preservative (Figs. 19 \& 20). Dorsal ground colour of head, body, limbs and tail buff-brown; top of head with numerous dark spots; labials suffused with lighter markings; a dark postorbital streak that extends beyond ear opening; neck and back with black spots that form longitudinal markings on neck and forebody; limbs with indistinct darker bars and spots; 11 dark and 10 light caudal bands, dark bands more than twice as wide as light bands; rest of ventral surfaces immaculate except some mottling toward flanks.

Variation (Fig 9). Female paratype (BNHS 2254) similar to holotype in general colouration but with less distinct longitudinal markings on neck; 10 dark bands on tail. Refer to Table 4 for further variation.

Distribution and Natural History. Cyrtodactylus nagalandensis sp. nov.is known only from the vicinity of Khonoma village, in the Naga Hills. The type series was collected from a road cutting after dark. We only saw two specimens of this species in two nights of searching. The surrounding forest habitats were mainly secondary forest.

Comparisons. Cyrtodactylus nagalandensis sp. nov. is a member of the mountain clade and is poorly supported as sister to the other Indian species in this clade, with uncorrected $p$-distance between the new species and other members of the clade 18.0-21.7\%. Cyrtodactylus nagalandensis sp. nov. can be diagnosed by the number of ventral scales (36 or 37 MVSR) from C. brevidactylus (45 MVSR), and Cyrtodactylus jaintiaensis sp. nov. (40-42 MVSR); by having fewer dorsal tubercle rows (16-18) from C. gansi (20-25 DTR) and Cyrtodactylus montanus sp. nov. (21-23 DTR); by its irregular dorsal colour pattern from C. chrysopylos (dorsal pattern of alternating brown and white bands). Major diagnostic characters for the new species and regional congeners are summarized in Table 3.

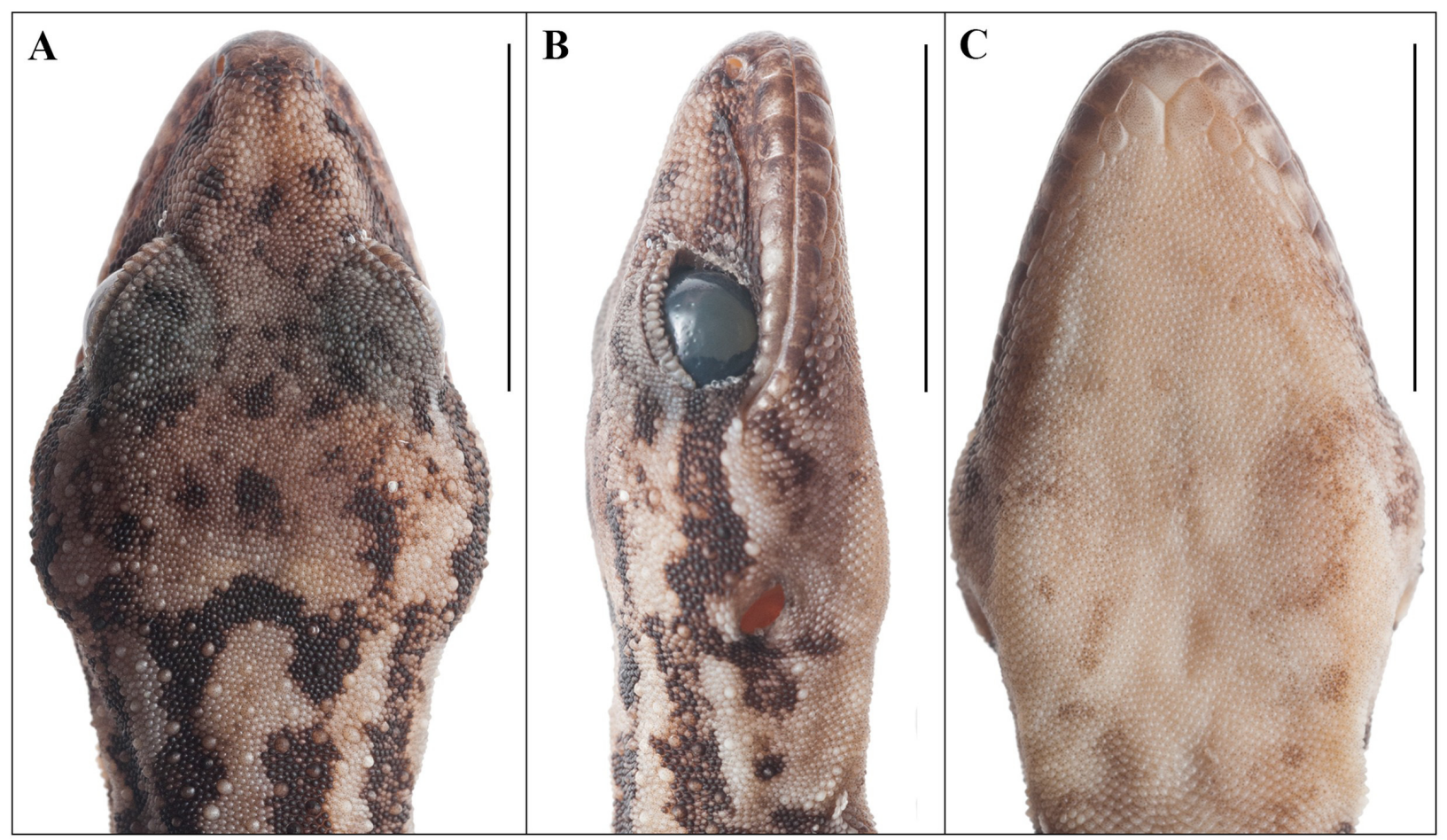

FIGURE 20. Head of Cyrtodactylus nagalandensis sp. nov. (adult female holotype, BNHS 2253), dorsal (A), lateral (B), and ventral $(\mathrm{C})$ view. Scale bars $10 \mathrm{~mm}$. 


\section{Discussion}

The description of these six new species brings the total number of Cyrtodactylus in the Himalayas and mainland Indo-Burma to 56, including 15 Indian species. This makes Cyrtodactylus one of the most speciose and microendemic groups of terrestrial vertebrates in the region, as is the case for the genus across much of its range (e.g. Bauer 2002, 2003; Agarwal et al. 2014, 2017; Grismer et al. 2018a, c). As predicted by Bauer (2003), most Cyrtodactylus in Indo-Burma appear restricted to individual mountains or hill ranges; the exceptions being the low elevation species C. ayeyarwadyensis and C. tripuraensis (Bauer 2003; Agarwal et al. 2017). The type locality of C. montanus sp. nov. and the most proximate locality of $C$. tripuraensis are less than $55 \mathrm{~km}$ apart, $C$. guwahatiensis sp. nov. is $<120 \mathrm{~km}$ from the type locality of $C$. septentrionalis sp. nov. and $<100 \mathrm{~km}$ from the type localities of C. khasiensis and C. jaintiaensis sp. nov., the type localities of the latter two species $\sim 50 \mathrm{~km}$ apart; indicative of fine scale distributional ranges and potentially undiscovered diversity. In fact, another undescribed species of Cyrtodactylus is distributed within $20 \mathrm{~km}$ of the type locality of C. guwahatiensis sp. nov. (Purkayastha, Agarwal, Bauer unpubl. data). Remarkably, the type series of the six new species, albeit small, are the result of just seven nights of fieldwork by a small team with an hour of sampling each night. The known elevational limit of Cyrtodactylus in India and Myanmar is $\sim 1500 \mathrm{~m}$ (Cyrtodactylus nagalandensis sp. nov.), which implies there is a vast area of unsampled lowland and mountain habitat. The data thus far clearly indicate that many more Cyrtodactylus species remain to be discovered in northeast India.

Three of the new species are from along the Brahmaputra River and three are from mountains south of the Brahmaputra, including the largest Cyrtodactylus from India and the fifth gecko to be described from a major Indian city, Guwahati (Gill 1997; Giri et al. 2009; Agarwal et al. 2016; Agarwal 2016). The new species described in this paper are members of the mountain clade (elevation averaged by species $740 \mathrm{~m}$, range 340-1300 m) and lowland clade (average $170 \mathrm{~m}$, range 6-900 m) (Agarwal et al. 2014). The lowland clade includes the only representatives of the south/east of Brahmaputra clade that are widely distributed, $C$. ayeyarwadyensis and $C$. tripuraensis, as well as the only species found north/west of the Brahmaputra, Cyrtodactylus septentrionalis sp. nov. The only species from the lowland clade to have made it into Myanmar is the coastal $C$. ayeyarwadyensis, and high mountains potentially act as barriers for this group (Agarwal et al. 2014). The mountain clade is more contiguously distributed across the Arakan-Yoma ranges in Myanmar and adjacent northeast India, but is restricted to areas south/east of the Brahmaputra (Agarwal et al. 2014).

The high species diversity in Myanmar is a combination of recent sampling efforts and the overlap in the region of both the Indo-Burma and Southeast Asia clades, the latter of which includes many recently discovered micro-endemic karst-associated species (Grismer et al. 2018a, b, c). The high diversity in Myanmar is also accompanied by a high degree of morphological variability, even within the Indo-Burma clade alone (e.g. Bauer 2002, 2003). Cyrtodactylus species in northeast India, however, are superficially similar in dorsal colouration and markings - grey or brown with irregular paired spots, bands or reticulations. However, these species are not cryptic - with a number of characters that separate the species including body size, the number of precloacal and femoral pores and variation in dorsal tuberculation (Table 3). Primary field surveys and the collection of large series of specimens will help stabilize the morphological characters of the new species described herein and contribute to understanding the biodiversity of this rich landscape. Though some of our diagnoses are based on minor pore differences and small sample sizes, it is likely that larger series of specimens will bear these results out. For example, in 11 of the 12 species described by Grismer et al. (2018a) that have a sample size of at least two, eight species have precloacal pore ranges that differ by $0-2$ pores, only two have a range of 3 and one has a range of 4. The description of these six new species leaves just Cyrtodactylus sp. Mizoram unnamed from within the mountain and lowland clades sampled by Agarwal et al. (2014), the description of which is also in preparation (Lalrinchhana, Agarwal, Giri unpubl. data).

\section{Acknowledgements}

Tarun Khichi, Aniruddha Datta-Roy, Abhijit Das, Garga Mohan Das, Ullasa Kodandaramiah, Duwaki Rangad, Ronald Lyngdoh Tron, and Kekhriesetuo Ziephru helped with fieldwork. We thank the Tripura Forest Department for permits and hospitality. IA thanks Praveen Karanth for lab support and Raman Kulkarni for office space to 
examine specimens. Partial funding came from the Department of Science and Technology (DST grant SR/SO/AS57/2009 to P Karanth) and the Ministry of Environment and Forests, Govt. of India; National Science Foundation (U.S.A.) grants DEB 0844523,1555968 and EF 1241885 (subaward 13-0632) to AMB. SM is currently funded by an Irish Research Council-Marie Skłodowska-Curie CAROLINE Fellowship (CLNE/2017/482). SM thanks B.H.C.K. Murthy, G. Ramakrishna and sections staff (ZSI) and Colin McCarthy and Patrick Campbell (NHMUK) for access to specimen collections. Lee Grismer shared his unpublished data on yet more new species from Myanmar and kindly waited for us to submit this paper.

\section{References}

Agarwal, I. (2016) Two new species of ground-dwelling Cyrtodactylus (Geckoella) from the Mysore Plateau, south India. Zootaxa, 4193 (2), 228-244. https://doi.org/10.11646/zootaxa.4193.2.2

Agarwal, I., Khandekar, A. \& Bauer, A.M. (2018a) A new bent-toed gecko (Squamata: Gekkonidae: Cyrtodactylus) from the Western Himalayas, Himachal Pradesh, India. Zootaxa, 4446 (4), 442-454. https://doi.org/10.11646/zootaxa.4446.4.2

Agarwal, I., Mahony, S., Giri, V.B., Chaitanya, R. \& Bauer, A.M. (2018b) Two new species of Cyrtodactylus Gray, 1827 (Squamata: Gekkonidae) with comments on name-bearing types from northeast India. Zootaxa, 4420 (3), 334-356. https://doi.org/10.11646/zootaxa.4420.3.2

Agarwal, I, Mirza, Z.A., Pal, S., Maddock, S.T., Mishra, A. \& Bauer, A.M. (2016) A new species of the Cyrtodactylus (Geckoella) collegalensis (Beddome, 1870) complex (Squamata: Gekkonidae) from Western India. Zootaxa, 4170 (2), 339-354. https://doi.org/10.11646/zootaxa.4170.2.7

Agarwal, I., Mistry, V. \& Athreya, R. (2010) A preliminary checklist of the reptiles of Eaglenest Wildlife Sanctuary, West Kameng district, Arunachal Pradesh, India. Russian Journal of Herpetology, 17, 81-93. https://doi.org/10.1016/j.ympev.2014.07.018

Agarwal, I., Bauer, A.M., Jackman, T.R. \& Karanth, K.P. (2014) Insights into Himalayan biogeography from geckos: a molecular phylogeny of Cyrtodactylus (Squamata: Gekkonidae). Molecular Phylogenetics and Evolution, 80, 145-155. https://doi.org/10.1016/j.ympev.2014.07.018

Ali, J.R. \& Aitchison, J.C. (2008) Gondwana to Asia: Plate tectonics, paleogeography and the biological connectivity of the Indian sub-continent from the Middle Jurassic through latest Eocene (166-35 Ma). Earth Science Reviews, 88, 145-166. https://doi.org/10.1016/j.earscirev.2008.01.007

Athreya, R. (2006) A new species of Liocichla (Aves: Timaliidae) from Eaglenest Wildlife Sanctuary, Arunachal Pradesh, India. Indian Birds, 2, 82-94.

Bauer, A.M. (2002) Two new species of Cyrtodactylus (Squamata: Gekkonidae) from Myanmar. Proceedings of the California Academy of Sciences, 53, 73-86.

Bauer, A.M. (2003) Descriptions of seven new Cyrtodactylus (Squamata: Gekkonidae) with a key to the species of Myanmar (Burma). Proceedings of the California Academy of Sciences, 54, 463-498.

Bauer, A.M., Masroor, R., Titus-McQuillan, J., Heinicke, M.P., Daza, J.D. \& Jackman, T.R. (2013) A preliminary phylogeny of the Palearctic naked-toed geckos (Reptilia: Squamata: Gekkonidae) with taxonomic implications. Zootaxa, 3599 (4), 301324. https://doi.org/10.11646/zootaxa.3599.4.1

Bouilhol, P., Jagoutz, O., Hancharb, J.M. \& Dudas, F.O. (2013) Dating the India-Eurasia collision through arc magmatic records. Earth and Planetary Science Letters, 366, 163-175. https://doi.org/10.1016/j.epsl.2013.01.023

Brennan, I.G., Bauer, A.M., Tri, N., Wang, Y.Y., Wang, W.Z., Zhang, Y.P. \& Murphy, R.W. (2017) Barcoding utility in a megadiverse, cross-continental genus: keeping pace with Cyrtodactylus geckos. Scientific Reports, 7 (5592), 1-11, Suppliment Info. https://doi.org/10.1038/s41598-017-05261-9

Britz, R., Sykes, D., Gower, D.J. \& Kamei, R.G. (2018) Monopterus rongsaw, a new species of hypogean swamp eel from the Khasi Hills in Northeast India (Teleostei: Synbranchiformes: Synbranchidae). Ichthyological Exploration of Freshwaters, 1086, 1-12.

Connette, G.M., Oswald, P., Thura, M.K., Connette, K.J.L., Grindley, M.E., Songer, M., Zug, G.R. \& Mulchay, D.G. (2017) Rapid forest clearing in a Myanmar proposed national park threatens two newly discovered species of geckos (Gekkonidae: Cyrtodactylus). PLoS ONE, 12, e0174432. https://doi.org/10.1371/journal.pone.0174432

Darevsky, I.S., Helfenberger, N., Orlov, N. \& Shah, K. (1997) Two new species of the genus Gonydactylus (Sauria: Gekkonidae) from eastern Nepal. Russian Journal of Herpetology, 4, 89-93. 
Das, A., Ahmed, M.F., Lahkar, B.P. \& Sharma, P. (2007) A preliminary report of reptilian mortality on road due to vehicular movements near Kaziranga National Park, Assam, India. Zoo's Print Journal, 22, 2742-2744. https://doi.org/10.11609/JoTT.ZPJ.1541.2742-4

Das, I., Tron, R.K.L., Rangad, D., Hooroo, R.N.K. (2010) A new species of Leptolalax (Anura: Megophryidae) from the sacred groves of Mawphlang, Meghalaya, north-eastern India. Zootaxa, 2339, 44-56.

Datta-Roy, A., Das, I., Bauer, A.M., Tron, R.K.L. \& Karanth, K.P. (2013) Lizard wears shades. A spectacled Sphenomorphus (Squamata: Scincidae), from the sacred forests of Mawphlang, Meghalaya, North-east India. Zootaxa, 3701 (2), $257-276$. https://doi.org/10.11646/zootaxa.3701.2.7

Devi, H.S., Pinokiyo, A. \& Borthakur, S.K. (2012) Vegetation cover and forest structure assessment in Rani and Garbhanga Reserve Forests, Assam using remote sensing and GIS. Pleione, 6 (2), 328-335.

Gill, E.V.S. (1997) Cyrtodactylus aravallensis, a new Gekkonidae from the Delhi Ridge. Journal of the Bombay Natural History Society, 94, 122-123.

Giri, V.B., Agarwal, I. \& Bauer, A.M. (2009) Designation of a neotype for Cnemaspis mysoriensis (Jerdon 1853) (Sauria: Gekkonidae), with a redescription and notes on its distribution and habitat. Russian Journal of Herpetology, 16, $256-264$.

Grismer, L.L., Wood, P.L., Thura, M.K., Zin, T., Quah, E.S., Murdoch, M.L., Grismer, M.S., Lin, A., Kyaw, H. \& Ngwe, L. (2018a) Twelve new species of Cyrtodactylus Gray (Squamata: Gekkonidae) from isolated limestone habitats in eastcentral and southern Myanmar demonstrate high localized diversity and unprecedented microendemism. Zoological Journal of the Linnean Society, 182, 862-959. https://doi.org/10.1093/zoolinnean/zlx057

Grismer, L.L., Wood, P.L. Jr., Thura, M.K., Zin, T., Quah, E.S.H., Murdoch, M.L., Grismer, M.S., Lin, A., Kyaw, H. \& Ngwe, L. (2018b) Phylogenetic taxonomy of Hemiphyllodactylus Bleeker, 1860 (Squamata: Gekkonidae) with descriptions of three new species from Myanmar. Journal of Natural History, 20, 1-98. https://doi.org/10.1080/00222933.2017.1367045

Grismer, L.L., Wood Jr, P.L., Thura, M.K., Quah, E.S., Murdoch, M.L., Grismer, M.S., Herr, M.W., Lin, A. \& Kyaw, H. (2018c) Three more new species of Cyrtodactylus (Squamata: Gekkonidae) from the Salween Basin of eastern Myanmar underscore the urgent need for the conservation of karst habitats. Journal of Natural History, 52, 1243-1294. https://doi.org/10.1080/00222933.2018.1449911

Kamei, R.G., Gower, D.J., Wilkinson, M. \& Biju, S.D. (2013) Systematics of the caecilian family Chikilidae (Amphibia: Gymnophiona) with the description of three new species of Chikila from northeast India. Zootaxa, 3666 (4), $401-435$. https://doi.org/10.11646/zootaxa.3666.4.1

Li, P.-P. (2007) Description of a new subspecies of Cyrtodactylus khasiensis from China. Acta Zootaxonomica Sinica, 32, 733737

Mahony, S. (2009a) A new species of Japalura (Reptilia: Agamidae) from northeast India with a discussion of the similar species Japalura sagittifera Smith, 1940 and Japalura planidorsata Jerdon, 1870. Zootaxa, 2212, 41-61.

Mahony, S. (2009b) Taxonomic status of Cyrtodactylus khasiensis tamaiensis (Smith, 1940) and description of a new species allied to C. chrysopylos Bauer, 2003 from Myanmar (Reptilia: Gekkonidae). Hamadryad, 34, 62-74.

Mahony, S., Ahmed, M., Hossain, M.K., Kabir, M.M. \& Hasan, M.K. (2009) Cyrtodactylus ayeyarwadyensis Bauer, 2003 (Reptilia: Gekkonidae) in Bangladesh with habitat details of new collection localities and a discussion of morphological variation. Salamandra, 45 (4), 245-250.

Mahony, S., Teeling, E.C. \& Biju, S.D. (2013) Three new species of horned frogs, Megophrys (Amphibia: Megophryidae), from Northeast India, with a resolution to the identity of Megophrys boettgeri populations reported from the region. Zootaxa, 3722 (2), 143-169.

https://doi.org/10.11646/zootaxa.3722.2.2

Mittermeier, R.A., Gil, P.R., Hoffmann, M., Pilgrim, J., Brooks, T., Mittermeier, C.G., Lamoreux, J. \& Fonseca, G.A.B. (2004) Hotspots Revisited: Earth's Biologically Richest and Most Endangered Terrestrial Ecoregions. Conservation International, Mexico City, 392 pp.

Pawar, S. \& Birand, A. (2001) A Survey of Amphibians, Reptiles, and Birds in northeast India. CERC Technical Report \#6. Centre for Ecological Research and Conservation, Mysore, $118 \mathrm{pp}$.

Purkayastha, J., Das, M. \& Sengupta, S. (2011) Urban herpetofauna: a case study in Guwahati City of Assam, India. Herpetology Notes, 4, 195-202.

Schleich, H.H. \& Kästle, W. (2002) Amphibians and Reptiles of Nepal. A.R.G. Gantner Verlag K.G., Ruggel, x + 1201 pp.

Shi, L. \& Zhao, H. (2010) A new species of Cyrtodactylus (Reptilia: Squamata: Geckkonidae) from Xizang Autonomous Region, China. Zootaxa, 2336, 51-60.

Silvestro, D. \& Michalak, I. (2012) raxmlGUI: A graphical front-end for RAxML. Organisms, Diversity and Evolution, 12 , $335-337$. https://doi.org/10.1007/s13127-011-0056-0

Sinha, A., Datta, A., Madhusudan, M.D. \& Mishra, C. (2005) Macaca munzala: a new species from western Arunachal Pradesh, northeastern India. International Journal of Primatology, 26, 977-989. https://doi.org/10.1007/s10764-005-5333-3

Slowinski, J.B. \& Wüster, W. (2000) A new cobra (Elapidae: Naja) from Myanmar (Burma). Herpetologica, 56, $257-270$.

Smith, M.A. (1935) The fauna of British India, including Ceylon and Burma. Reptilia and Amphibia. Vol. II. Sauria. Taylor and 
Francis, London, xiii + 440 pp., 1 pl.

Sondhi, S. \& Ohler, A. (2011) A blue-eyed Leptobrachium (Anura: Megophryidae) from Arunachal Pradesh, India. Zootaxa, $36,28-36$.

Stamatakis, A. (2006) RAxML-VI-HPC: Maximum likelihoodbased phylogenetic analyses with thousands of taxa and mixed models. Bioinformatics, 22, 2688-2690.

https://doi.org/10.1093/bioinformatics/btl446

Tamura, K., Peterson, D., Peterson, N., Stecher, G., Nei, M. \& Kumar, S. (2011) MEGA5: molecular evolutionary genetics analysis using maximum likelihood, evolutionary distance, and maximum parsimony methods. Molecular Biology and Evolution, 28, 2731-2739.

https://doi.org/10.1093/molbev/msr121

Uetz, P., Freed, P. \& Hošek, J. (Eds.) (2018) The Reptile Database. Available from: http://www.reptile-database.org (accessed 25 August 2018)

Wood, P.L. Jr., Heinicke, M.P., Jackman, T.R. \& Bauer, A.M. (2012) Phylogeny of bent-toed geckos (Cyrtodactylus) reveals a west to east pattern of diversification. Molecular Phylogenetics and Evolution, 65, 992-1003.

https://doi.org/10.1016/j.ympev.2012.08.025

APPENDIX 1. List of material examined

Cyrtodactylus ayeyarwadyensis: CAS 226154 (male holotype); CAS 216506, CAS 226149-226150, CAS 226153 (male paratypes); CAS 226147. USNM JBS8637, CAS 226152, CAS 226156 (female paratypes).

C. annandalei: CAS 215722 (male holotype); CAS 215757, CAS 215749 (female paratypes).

C. bhupathyi: BNHS 2255 (holotype); BNHS 2256 (paratype), females.

C. brevidactylus: CAS 214104 (male holotype); CAS 214120, CAS 214105 (female paratypes).

C. chrysopylos: CAS 226141 (female holotype).

C. gansi: CAS 222414 (male holotype); CAS 222411-22242, CAS 222414 (male paratypes); CAS 222413 (female holotype).

C. gubernatoris: ZSI K17275 (male holotype); BNHS 2207 (male), BNHS 2208-2210 (females).

C. himalayicus: ZSI K15716 (male holotype); ZSI K19546 (female).

C. khasiensis: BMNH 1906.8.10.4 (female lectotype); ZSIK6199 (female paralectotype); BNHS 2249-2252

C. mandalayensis: BMNH 1900.9.20.1 (male holotype).

C. russelli: CAS 226137 (male holotype); CAS 226140 (female paratype).

C. slowinskii: CAS 210214 (male holotype); CAS 210217, CAS 210219, CAS 215474, CAS 215661, USNM 548142 (male paratypes); CAS 210212-210213, CAS 210215-210216, CAS 210218 (female paratypes).

C. tamaiensis: BMNH 1946.823.22 (male holotype).

C. tripuraensis: BNHS 2244 (male holotype); BNHS 2236-2238, BNHS 2242-BNHS 2243, BNHS 2245 (male paratypes), BNHS 2230, BNHS 2239-2241 (female paratypes).

C. wakeorum: CAS 221935 (female holotype). 